\title{
Spectral artefacts post sputter-etching and how to cope with them - a case study of XPS on nitride-based coatings using monoatomic and cluster ion beams
}

\author{
Erik Lewin ${ }^{\mathrm{a}, \mathrm{b}, *}$, Jonathan Counsell ${ }^{\mathrm{c}}$, Jörg Patscheider ${ }^{\mathrm{a}, \#}$ \\ ${ }^{a}$ Laboratory for Nanoscale Materials Science, Empa, Überlandstrasse 129, CH-8600 Dübendorf, Switzerland \\ ${ }^{\mathrm{b}}$ Inorganic chemistry, Department of Chemistry - Ångström Laboratory, Uppsala university, Box 538, SE-751
}

21 Uppsala, Sweden

${ }^{c}$ Kratos Analytical Ltd, Trafford Wharf Road, Manchester, M17 1G, United Kingdom

\begin{abstract}
The issue of artefacts due to sputter-etching has been investigated for a group of AlN-based thin film materials with varying thermodynamical stability. Stability of the materials was controlled by alloying AlN with the group 14 elements $\mathrm{Si}, \mathrm{Ge}$ or $\mathrm{Sn}$ in two different concentrations. The coatings were sputter-etched with monoatomic $\mathrm{Ar}^{+}$with energies between 0.2 and $4.0 \mathrm{keV}$ to study the sensitivity of the materials for sputter damage. The use of $\mathrm{Ar}_{\mathrm{n}}{ }^{+}$clusters to remove an oxidised surface layer was also evaluated for a selected sample. The spectra were compared to pristine spectra obtained after in-vacuo sample transfer from the synthesis chamber to the analysis instrument. It was found that the all samples were affected by high energy $(4 \mathrm{keV}) \mathrm{Ar}^{+}$ions to varying degrees. The determining factors for the amount of observed damage were found to be the materials' enthalpy of formation, where a threshold value seems to exist at approximately $-1.25 \mathrm{eV} /$ atom $(\sim-120 \mathrm{~kJ} / \mathrm{mol}$ atoms $)$. For each sample, the observed amount of damage was found to have a linear dependence to the energy deposited by the ion beam per volume removed material. Despite the occurrence of sputter-damage in all samples, etching settings that result in almost artefact-free spectral data were found; using either very low energy (i.e. $200 \mathrm{eV}$ ) monoatomic ions, or an appropriate combination of ion cluster size and energy. The present study underlines that analysis post sputter-etching must be carried out with an awareness of possible sputter-induced artefacts.
\end{abstract}

(242 words, 1538 characters)

\section{Keywords}

- Sputter artefacts

- Ion-etching

- X-ray photoelectron spectroscopy, XPS

- Gas-cluster ion beams, GCIB

- Coating materials

- Nitrides

\section{Highlights}

- XPS analysis performed after different ion-etching methods

- Nitride coatings with different (meta)stability investigated

- Sputter-induced artefacts strongly dependent on material (average) formation enthalpy

- Sputter-induced artefacts linearly dependent on energy deposited per removed volume

- Artefact free spectra can be obtained by both monoatomic and polyatomic ion beams

*) Corresponding author, electronic mail: erik.lewin@kemi.uu.se

\#) Presently at Evatec AG, Trübbach, Switzerland

This document is the accepted manuscript version of the following article:

Lewin, E., Counse11, J., \& Patscheider, J. (2018). Spectral artefacts post sputter-etching and how to cope with them - A case study of XPS on nitride-based coatings using monoatomic and cluster ion beams. Applied Surface science, 442, 487-500. http://doi.org/10.1016/j.apsusc.2018.02.191 


\section{Content}

1. Introduction 2

2. Materials 5

3. Experimental details 5

4. Results

4.1 Ex-situ experiments: preferential sputtering by monoatomic $\mathrm{Ar}^{+}$etching

4.2 In-situ sample transfer: analysis of pristine surfaces and effects of monoatomic $\mathrm{Ar}^{+}$etching 7

4.2.1. $\mathrm{Al} 2 \mathrm{p}$ and $\mathrm{N} 1 \mathrm{~s}$ core level spectra (all samples)

4.2.2. Al-Si-N - Si 2p core level spectra

4.2.3. Al-Ge-N - Ge $2 p$ and $3 \mathrm{~d}$ core level spectra

4.2.4. Al-Sn-N - Sn 3d core level spectra

4.2.5. Quantification of sputter damage

4.2.6. Valence band spectra

4.3. Ex-situ experiments: removal of surface oxides with $\mathrm{Ar}_{n}{ }^{+}$cluster ions 9

5. Discussion

5.1 Observed damage by monoatomic etching

5.2 Comparison of etching by GCIB to monoatomic $\mathrm{Ar}^{+}$

5.3 Sputter sensitivity and thermodynamic stability

5.4 Limits to acquisition of artefact-free surface information

Summarising remarks

7. Acknowledgements

8. References

\section{Introduction}

Development of novel materials is a key foundation on which modern technology rests. To be able to understand the structure and the properties of old, and future materials, the use of different analytical techniques to determine the material composition, bonding, structure and morphology is essential. Almost all modern materials analysis techniques are based on irradiating the sample with either particles (electrons, ions, neutrons) or photons (X-rays, UV, visible or infrared light). Additionally, the sample may need preparation before analysis, including irradiating the sample with ions. Such irradiation can have sufficient energy to alter the material - thus post irradiation the surface analysed is no longer the pristine as-received material.

X-ray photoelectron spectroscopy, XPS, is a unique tool for materials analysis. XPS yields information regarding elemental identification of all elements beyond $\mathrm{He}$, quantitative elemental concentrations and information on the chemical environment of each element. Furthermore XPS is a surface sensitive technique with an information depth of three times the attenuation length (AL) of the photoelectrons analysed. For most lab instruments, which commonly use Al K $\alpha$ radiation (hv=1486.7 $\mathrm{eV}$ ), the $\mathrm{AL}$ is a few nm, e.g. for N 1s photoelectrons from AlN is less than $2.5 \mathrm{~nm}$. XPS is an established analytical technique for surface analysis, but there are challenges regarding surface contamination and oxidation.[1]

Since most samples are air-exposed before analysis, they have an oxidised surface layer and adsorbed contaminants. In order to employ surface analytical techniques such as Auger spectroscopy (AES) and XPS to probe the bulk of the material, this surface layer needs to be removed. Such removal is typically performed using an ion source to sputter-etch the surface of the sample. In such sample preparation chemical bonds will be broken. During this process the bulk structure intended for analysis may also be altered. The extent of these changes remains a challenge for sputter cleaning delicate surfaces. The question is how severe are these changes: is the structure and/or chemistry of the analyte changed and if so to what extent? Such modifications may result in changes to the spectral form of the pre and post sputtered materials. For clarity, non-original features will in the following be denoted as artefacts or sputter damage.

Artefacts due to sputter etching have been well known for a long time, and can be divided into two types depending whether the sample composition is changed or not. Changes in the sample 
composition occur due to preferential sputtering, where one element is more easily (preferentially) ejected from the sample than other elements. This is often more pronounced in materials where there is a large mass difference between the elements, as well as when the lighter element can form stable gaseous species and thus exit the sample. Preferential sputtering thus typically leads to a change in sample composition as well as a change in chemical environment and/or oxidation state of the remaining elements also giving changes in the spectra of remaining elements. Ceramic materials containing elements that can form gaseous species, and/or contain elements that can have several different oxidation states, e.g. $\mathrm{NiO}[2], \mathrm{Fe}_{2} \mathrm{O}_{3}[3], \mathrm{WO}_{3}[4,5], \mathrm{MoO}_{3}[5,6], \mathrm{Ta}_{2} \mathrm{O}_{5}$ [7], $\mathrm{TiO}_{2}$ [8], GaN[9], $\mathrm{BN}[10]$, are known to be susceptible to preferential sputtering, even if the original material is thermodynamically stable.

However, even if no preferential sputtering occurs, the material can be damaged as bonds are broken and atoms move in the collision cascade that follows the impact of an ion in the keV energy range. This can then lead to the bonding in the material becoming distinctly different compared to prior ion bombardment, thus causing changes to the XPS spectra. Generally organic and polymeric materials, e.g. plexiglass (PMMA) and polyimide [11, 12], and also graphene[13], are known to undergo sputter damage changing the local chemistry upon ion radiation. Also $\mathrm{Ar}^{+}$etching of Si wafer has been shown to affect the valence band in this case due to ion implantation [14]. Reports on artefacts in sulphide [15-17] and carbide [18] based materials as a result of both $\mathrm{Ar}^{+}$sputter etching prior to XPS analysis, and as a result of $\mathrm{e}^{-}$radiation in the TEM analysis $[19,20]$ are further examples of damage where the local chemical environment is changed, with or without significant preferential sputtering.

Many models as well as simulation schemes of ion-matter interaction have been presented, see e.g. the review by Ignatova et al.[21]. Simpler models often incorporate the mass difference in the irradiated material and surface binding energy to reproduce preferential sputtering, see Malherbe et al. [22]. More complex schemes employ force field models and either Monte Carlo or molecular dynamics simulations [21]. For many compounds it is however difficult to determine surface binding energies, and complex compounds may require specific force field models, limiting the predictive powers of a general model. An alternative initial approach considering the chemical bonding uses the enthalpy of formation [23-27]. For example, Holm and Storp [23] and Christie et al. [24] analysed inorganic salts and found that the free energy of formation was a key parameter for the sensitivity to sputter damage. Such an approach also has the advantage that considering bond energies in compounds also opens up for correlations to other damage than preferential sputtering of one element, such as the decomposition of metastable phases.

From a materials analysis point of view, such as sputter-etching to remove a surface oxide the main question is to what degree data acquired with standard methods can be trusted, and how this can be evaluated. This leads to two new questions: How can one obtain spectra of pristine bulk material and how can artefacts be minimised?

To attain spectra from pristine material, there are in principle two methods. The first option is to ensure that no surface contamination or oxidation occurs prior to analysis. Primarily this is achieved using in-situ measurements in ultra-high vacuum (UHV), combining synthesis and analysis equipment, or by ensuring inert transfer from the synthesis equipment to the analysis instrument (for minimal contamination preferably an in-vacuo transfer). Such methods have for example been used for the analysis of pure TiN [28] and for electrode materials from batteries after use [29]. Another recently explored method to avoid contamination and oxidation is to deposit a thin capping layer of a light element (e.g., $\mathrm{Al}$ ), that is thin enough for photoelectrons from the pristine material below to escape during subsequent analysis [30, 31]. Also other techniques such as in-situ mechanical polishing[32] and thermal shock induced adhesion failure[33] has been used to gain access to non-oxidised material without using sputter etching. The two latter methods do however require bespoke equipment.

The other option to avoid the need to remove the surface oxide is to increase the information depth of the analysis so that analysis probes below any surface contamination and oxidation. This can achieved by increasing the X-ray energy and therefore the kinetic energy of the photoelectrons [34]. To obtain sufficient information depth hard X-rays with an energy of at least $6 \mathrm{keV}$ are required. This method is known as hard X-ray photoelectron spectroscopy (HAXPES) and thus requires a non-standard X-ray source and an adapted electron analyser. This method is mainly conducted at specialised synchrotron beamlines. There are commercial or semi-commercial X-ray sources with Ag (using the L $\alpha$ line at $2984.4 \mathrm{eV}$ ) [35], $\mathrm{Cr}$ (using the $\mathrm{K} \alpha$ line at $5414.7 \mathrm{eV}$ ) [36], and liquid $\mathrm{Ga}$ (using the $\mathrm{K} \alpha$ line at 9251.7 
eV) [37] anodes that give varying degree of HAXPES capabilities to laboratory instruments. However, the X-rays from the Ag source are not energetic enough to be useful for all materials, and the availability of the $\mathrm{Cr}$ and $\mathrm{Ga}$ sources is very limited. HAXPES has been used both to specifically study sputter-damage as well as to avoid the use of sputter-etching on sensitive materials, see e.g. $[15,18$, $38]$.

If one cannot avoid removing the oxidised surface layer, the obvious way to reduce the amount of damage that may occur upon sputter etching, is to reduce the energy of ions used to bombard the sample. Such an approach has been used with several materials with varying degree of success $[9,10$, $18,39]$. Reducing the energy of the ion beam will, however, always lead to a significant reduction in etch rate.

A new approach, which has been gradually developed around the turn of the century, is the use of polyatomic ions for sputter etching. The initial applications used molecular carbon and hydrocarbon ions, primarily $\mathrm{C}_{60}$ bucky balls and $\mathrm{C}_{24} \mathrm{H}_{12}$ coronene, which were found to perform well for depthprofiling polymeric materials [11]. However, these carbon-based molecules do not perform well on ceramic materials due to low sputtering yield and unwanted carbide formation. A more recent development is the use of inert gas clusters such as $\mathrm{Ar}_{n}{ }^{+}$with $\mathrm{n}$ up to 5000, which avoids the risk of compound formation due to the use of noble gas atoms [40]. These sources are called gas-cluster ion sources (GCIBS). Cluster formation occurs via supersonic adiabatic isentropic expansion of Ar gas into a vacuum through an aperture. The condensation results in a distribution of cluster sizes. Postionisation mass selection is performed using a mass filter. A more detailed description of the mechanics of cluster formation has been given previously $[8,40]$. The clusters are accelerated to a high kinetic energy (several keV) and thus propelled towards the sample. Since the clusters disintegrate upon impact on the sample surface, they transform to a bombardment with many particles of comparably low average energy per particle. For example, an $\mathrm{Ar}_{2000}{ }^{+}$cluster accelerated to a kinetic energy of $15 \mathrm{keV}$ will thus give a bombardment of $2000 \mathrm{Ar}$ atoms, with an average energy of $7.5 \mathrm{eV}$ each. This will lead to a shallow damage zone with very little bulk penetration, and thus less damaged material in the probed analysis volume. However, the impact of the ion cluster also causes non-linear sputtering and implantation effects, which are fundamentally different from impact of monoatomic ions and include a very localised spike in pressure and temperature [40]. The use of $\mathrm{Ar}_{n}{ }^{+}$clusters have in many cases been shown to successfully reduce, minimise or remove the issue of sputter-damage for a wide range of materials, such as polymers [12], semiconductor materials [41], and oxides [3, 7, 8]. It has also been shown that the cluster size and energy are essential parameters in order to minimise artefacts in the spectra $[3,41]$.

The present study investigates the issue of artefacts due to sputter-etching for a group of recently studied AlN-based thin film materials from a material analysis point of view. The studied materials are based on pure AIN (a thermodynamically stable phase with strong bonds) and the introduction of a group 14 (formerly known as group IV) elements to form ternary Al-X-N materials, with X being Si, $\mathrm{Ge}$ or $\mathrm{Sn}$ [42-46]. This series of materials exhibits microstructures with solid solutions beyond the thermodynamic equilibrium and nanocomposite structures, as well as varying average bond strengths. These materials are thus typical examples where material description through force field models is, if not impossible, very challenging and require special expertise (particularly in the case where new materials are synthesised for the first time). From a materials analysis point of view it would hence be convenient if a simpler approach could be used to guide the selection of analysis parameters for new or unknown materials. The present study presents observed correlations between the extent of sputter damage and ion beam parameters and estimations of material stability via the enthalpy of formation. The presented results demonstrate general trends of the studied type materials, but the implications on how to predict sputter damages are relevant also for other materials systems. For this study in-vacuo sample transfer from the synthesis chamber to the analysis instrument was used to obtain reference spectra of pristine material. Sputter-etching with monoatomic $\mathrm{Ar}^{+}$with energies between 0.2 and 4.0 $\mathrm{keV}$ were used to study the sensitivity of the materials for sputter damage. The use of $\mathrm{Ar}_{n}{ }^{+}$clusters to remove an oxidised surface layer was evaluated for a selected sample; it was found that (almost) artefact-free spectral data could be attained using this method.

The paper is organised in such a way that background information is introduced for the studied materials and experimental details. The results are divided into three parts, first observations on preferential sputtering made from ex-situ experiments, followed by the main study results obtained 
from in-situ measurement and analysis of photoelectron core levels. This part first considers the core levels that are common for all studies samples ( $\mathrm{Al} 2 \mathrm{p}$ and $\mathrm{N} \mathrm{1s}$ ), followed by the core levels specific for the different materials systems ( $\mathrm{Si} 2 \mathrm{p}, \mathrm{Ge} 2 \mathrm{p}$ and 3d, and Sn 3d). From this, quantification of the observed sputter-damage is made, before further observations connected to the valence band spectra are given. The last part of the results are from ex-situ experiments where gas cluster ion beams were used to remove the oxidised surface from one of the previously studied samples. This is followed by a section where the results are compared, discussed and put into perspective. Finally the paper is summarised with comments and recommendations for the analyst.

\section{Materials}

The materials used in the present study have been described in detail in previous publications [42-45, 47], so here only a brief summary is given. The starting point of the sample series is AIN, a thermodynamically stable phase [48]. The series is the created by co-deposition with a group 14 (previously known as group IV) element ( $\mathrm{Si}, \mathrm{Ge}$ or $\mathrm{Sn}$ ) in various elemental concentrations. These group 14 elements form nitrides, but their stability decreases rapidly downward in the group [48, 49], see Table 1. For tin nitride no data is available, but the reported compound is most likely metastable with respect to the elements. The samples studied here have group 14 element concentration of between 0 and 26 at.\%, and have been carefully analysed with XPS, XRD and electron microscopy. Composition and microstructures of the samples in the present study are summarised in Table 2. Using the normalised enthalpy of formation for the binary nitrides (see Table 1) and the sample compositions, a weighted average enthalpy of formation has been estimated for each sample. This calculation assumes the samples are mixtures of stoichiometric binary nitrides, and the estimated values are thus rough approximations.

\section{Experimental details}

Coatings were synthesised by reactive magnetron sputtering in an AJA 1500C sputter system [42-45, 47]. The base pressure during the depositions was $2.0 \times 10^{-8}$ mbar or below. For the present study samples were reactively sputter deposited on $\mathrm{Si}(100)$ by confocal codeposition from two elemental 2" targets of $\mathrm{Al}$ and ( $\mathrm{Si}, \mathrm{Ge}$ or $\mathrm{Sn})$. All depositions were conducted at constant pressure of 4.0-6.0 $\times 10^{-3}$ mbar (depending on the alloying element). Also gas flows were varied depending on alloying element with a relative amount $\mathrm{N}_{2}$ of 35 to $100 \%$. Higher pressures and higher reactive gas percentage was used for increasing mass of the alloying element. Depositions were conducted at $200{ }^{\circ} \mathrm{C}$, and in the case of $\mathrm{Sn}$ as alloying element also with the substrate holder at a $-60 \mathrm{~V}$ RF bias. The composition was varied by applying different powers to the two magnetrons. For each ternary materials system two samples were deposited with about 10 and 20 at.\% alloying element, respectively. Also a binary AlN sample was deposited for comparison. Deposition time was constant at $30 \mathrm{~min}$, resulting in coatings thicknesses between $\sim 80$ and $\sim 270 \mathrm{~nm}$.

Immediately after deposition the samples were transferred in-vacuo at pressures below $10^{-9} \mathrm{mbar}$ to the XPS spectrometer using a UHV transfer system described previously [50]. During the subsequent transfer from the storage chamber to the spectrometer the samples were exposed to $2 \times 10^{-8} \mathrm{mbar}$ for $<1$ min. This procedure ensured that the surface of the samples were not oxidised and that the material could be analysed without sputter-etching.

For comparison, additional samples from the same deposition were removed from the system and thus exposed to air resulting in surface oxidation. One sample was used for ex-situ experiments to evaluate if sputter-etching using an $\mathrm{Ar}_{\mathrm{n}}{ }^{+}$cluster source could be used to obtain defect-free spectra after removal of the surface oxide.

Both the spectrometers used for XPS (specified below) were calibrated against reference samples of $\mathrm{Au}, \mathrm{Ag}$ and $\mathrm{Cu}$, according to ISO 15472 [51]. As the samples are electrically insulating, they were measured under constant charge neutralization (specified for respective spectrometer below). In all analyses the $\mathrm{Al} 2 \mathrm{p}$ peak was chosen as charge reference and set to a binding energy of $73.6 \mathrm{eV}$ (which is the literature value for $\mathrm{Al} 2 \mathrm{p}$ in AlN) $[52,53]$; all spectra were shifted accordingly. Other alternatives were also considered, but the $\mathrm{Al} 2 \mathrm{p}$ peak position is from a chemical point of view 
expected to be least effected to the material, and the approach delivers consistent results as shown by the authors in previous publications [44-46].

For all in-situ experiments and for all experiments using monoatomic $\mathrm{Ar}^{+}$ion etching XPS was performed using a Physical Electronics Quantum 2000 spectrometer. This instrument employs monochromatic $\mathrm{Al} \mathrm{K} \alpha$ radiation $(\mathrm{h} v=1486.7 \mathrm{eV}$ ) and with the used settings provides an energy resolution $\sim 0.65 \mathrm{eV}$. For the present experiments the analysis spot was set to a diameter of $200 \mu \mathrm{m}$, and an electron take-off angle of $45^{\circ}$ was used. Charge neutralization was performed with an electron flood gun and low energy $\mathrm{Ar}^{+}$ions, as described in reference [54]. This method will without user input provide stable measurement conditions, but spectra require post measurement charge referencing, specified above. For compositional analysis using data from the Quantum 2000, custom sensitivity factors were derived from reference measurements using a combination of elastic recoil detection analysis (ERDA) and Rutherford backscattering (RBS), details are given in previous publications [4446].

For the in-vacuo transferred samples, spectra were first obtained on the surface of the samples (these spectra henceforth denoted as "pristine"), and after sputter-etching using monoatomic $\mathrm{Ar}^{+}$with three different energies: $200 \mathrm{eV}, 1 \mathrm{keV}$ and $4 \mathrm{keV}$ (further details are given in Table 3). The system geometry has an incident angle of $\mathrm{Ar}^{+}$ions of $45^{\circ}$ to the sample surface; the ion beam was in all three cases rastered over a $1 \times 1 \mathrm{~mm}$ area. Ion beam currents given in Table 3 were measured with a Faraday cup in the system and are typical values for the used settings. The etching time was varied from $35 \mathrm{~s}$ to ca. $1 \mathrm{~h}$ in order to achieve the same analysis depth of $\sim 30 \mathrm{~nm}$. Sputter-etch rates for the different settings were calibrated using a thin Al-Si-N coating of known thickness. Thus the stated analysis depth will be the same for the different etch settings, but vary slightly between samples due to different composition giving slightly different etch-rates. All four analyses on the samples were performed on four different spots sufficiently separated to ensure no cross-exposure to $\mathrm{Ar}^{+}$ions of other energy than intended, but still within a small enough area $(\mathrm{ca} 5 \times 10 \mathrm{~mm})$ to ensure no variation in coating composition. Additionally survey spectra and sputter-depth profiles using $200 \mathrm{eV} \mathrm{Ar}{ }^{+}$were obtained for compositional analysis. Bulk compositions were determined from these depth profiles.

Ex-situ experiments to evaluate the use of $\mathrm{Ar}_{n}{ }^{+}$clusters were performed using a Kratos AXIS Supra spectrometer using a monochromatic $\mathrm{Al} \mathrm{K} \alpha$ source, which has a spectral resolution of $0.44 \mathrm{eV}$. The instrument uses an electron take-off angle of $90^{\circ}$ to the sample surface; this set of experiments was conducted using an analysis spot with a diameter of $110 \mu \mathrm{m}$. The system uses an automated charge neutralizer system [55] to maintain stable measurement conditions for non-conductive samples. Also in this case no user input to the neutralisation is required, but post measurement charge referencing is.

The instrument was equipped with a gas-cluster ion source, which uses post-ionisation mass selection by a Wien filter, allowing for cluster size between $n=250$ and $n=5000$. Cluster energy is determined by the accelerating voltage, tuneable between $0.25 \mathrm{kV}-20 \mathrm{kV}$. In the present experiments two ion beam settings were used: one with a large cluster $(\mathrm{n}=5000)$ and low kinetic energy $(5 \mathrm{keV})$, and one with a smaller cluster size $(\mathrm{n}=2000)$ and a higher kinetic energy $(20 \mathrm{keV})$, see Table 3 for details. In both cases the beam was rastered over an area of $2 \times 2 \mathrm{~mm}$. Sputter-etching was performed, until the oxygen peak was significantly reduced in intensity, to less than $6 \%$ and $35 \%$ of the original peak area, for the $20 \mathrm{keV} \mathrm{Ar}_{1000}{ }^{+}$and $5 \mathrm{keV} \mathrm{Ar}{ }_{2000}{ }^{+}$settings, respectively. Thus the spectra are obtained after most of the surface oxidised layer had been removed. The resulting sputter depths, estimated via rate calibration on a $\mathrm{Ta}_{2} \mathrm{O}_{5}$ thin film standard are also given in Table 3. These depths are smaller than for the monoatomic sputter etching; however the reduction of the oxygen signal shows that they are relevant for the analysis.

Fitting of experimental XPS spectra into their base components was carried out using the XPS Peak software [56]. A Shirley type background was used, and a Voigt profile with a 15\% Lorentzian contribution was typically used, although asymmetric contributions were allowed in some cases. Fits were performed simultaneously on several spectra obtained after different $\mathrm{Ar}^{+}$ion bombardments, where the peak shapes were fixed and the intensities were allowed to vary to give an estimate of the different contributions as a function of ion bombardment.

Simulations of the $\mathrm{Ar}^{+}$bombardment of the materials were performed using the SRIM 2013 software package [57] in order to estimate the range of damage and $\mathrm{Ar}^{+}$implantations, and the energy loss depth profiles. This package uses a Monte-Carlo code to simulate the stopping and range of ions in 
matter using an amorphous target and a quantum-mechanical treatment of ion-atom collisions [58]. Parameters used for the simulations were kept as close to the experimental conditions as possible, with $\mathrm{Ar}^{+}$of different energies hitting an $\mathrm{Al}_{0.5} \mathrm{Ge}_{0.5} \mathrm{~N}$ target at a $45^{\circ}$ angle, and calculation of full recoil cascades and sputtering. For the simulations $10000 \mathrm{Ar}^{+}$ions were used. The impact of $\mathrm{Ar}_{\mathrm{n}}{ }^{+}$clusters is more complex and cannot easily be simulated in readily available software, and is thus beyond the scope of the present study.

The information depth of photoelectrons can be estimated by considering the photoemission angle, setting the maximum escape length to 3 times the attenuation length of the photoelectrons, of a certain kinetic energy in a certain material. The attenuation length is generally $70-95 \%$ of the inelastic mean free path, which is easier to calculate as is dependent on fewer parameters. As the studied materials are rather complex, and varying composition, the information depth has been estimated for AlN using the inelastic mean free path instead, calculated using the software Quases [59] which employs the TPP$2 \mathrm{M}$ equation [60]. This approach will not give an exact value, but is sufficient for the discussion at hand.

\section{Results}

\subsection{Ex-situ experiments: preferential sputtering by monoatomic $\mathrm{Ar}^{+}$etching}

Sputter-depth profiles using different $\mathrm{Ar}^{+}$ion energies on air-transferred samples revealed that samples in the Al-Ge-N systems suffered from preferential sputtering of $\mathrm{N}$. This is evident from the calculated concentrations (using the same sensitivity factors), which show a decrease of the $\mathrm{N}$ content with increasing $\mathrm{Ar}^{+}$ion energies, especially at high alloying contents. For a sample with 28 at. $\%$ Ge the measured $\mathrm{N}$ content decreased from 52 at.\% (using $200 \mathrm{eV} \mathrm{Ar}^{+}$) to 40 at.\% (using $4 \mathrm{keV} \mathrm{Ar}{ }^{+}$). This indicates that $\mathrm{N}$ is preferentially removed from the material, and that this occurs to a larger degree, when high ion energies are used for etching. For the combination of high ion energies and high alloying content a significant fraction of $\mathrm{N}$ (about 20\%) is removed. For the samples Al-Si-N system this effect was very small, in the range of the experimental reproducibility, thus indicating a very low degree of preferential sputtering. For the Al-Sn-N system, depth profiles were (due to limited instrument availability) only obtained using the lowest possible ion energies $(200 \mathrm{eV})$ to minimise the issue. Thus no evaluation of the preferential sputtering can be made for this system. However, considering the relative stabilities of $\mathrm{Ge}_{3} \mathrm{~N}_{4}$ and $\mathrm{SnN}_{\mathrm{x}}$ and core level spectra presented below, it is reasonable to assume that the same type of preferential sputtering as in the Al-Ge-N system would be observed in this system as well. All presented compositional data were obtained from profiles using $200 \mathrm{eV} \mathrm{Ar}^{+}$and custom sensitivity factors calibrated against ERDA / RBS measurements. Thus the compositions presented here are correct to within a few atomic percent.

\subsection{In-situ sample transfer: analysis of pristine surfaces and effects of monoatomic $\mathrm{Ar}^{+}$etching}

Spectra from the measurements conducted after in-situ transfer are presented in Fig. 1-4, 6 and 9 The spectra from the pristine surface (green, dotted lines) of the samples show the undamaged material, while the spectra after different etching (blue, orange and red solid lines) exhibit varying degrees of difference compared to the pristine spectra, which are shown in the following to be a consequence of sputter-damage, i.e. artefacts generated by ion etching.

\subsubsection{Al 2p and $\mathrm{N} 1 \mathrm{~s}$ core level spectra (all samples)}

The Al $2 p$ and $N$ 1s spectral regions (Fig. 1-2) show very small differences between the pristine and sputter-etched material for all studied materials. This indicates that the bonding environment of $\mathrm{Al}$ and the $\mathrm{N}$ in the material does not change. The largest difference in these spectra are a narrowing of the $\mathrm{N} 1 \mathrm{~s}$ peaks for Al-Ge-N and Al-Sn-N material subjected to high energy $\mathrm{Ar}^{+}$ions. This indicates that the range of chemical environments for nitrogen decreases. A cause of this decrease can be the preferential sputtering of nitrogen in certain chemical environments, i.e. bonded to Ge or Sn. Such an explanation is consistent with the observations of preferential sputtering made above. The observed variations of the Al $2 \mathrm{p}$ and $\mathrm{N} 1 \mathrm{~s}$ spectra for the binary AlN sample, (possibly also the Al-Si-N samples) give an indication of the uncertainties of the used experimental set-up and charge-referencing method. The core-level spectra of the alloying elements are described below and presented in Fig. 3 5 . Each materials system will be presented independently, and trends discussed later.

\subsubsection{Al-Si-N - Si 2p core level spectra}


For the Si 2p region (Fig. 3) two different artefacts are noted: firstly, there is a small, although systematic shift of the peak to lower binding energy (101.4-101.1 eV and $101.2-100.9 \mathrm{eV}$, for low and high alloying content, respectively) as the material is subjected to higher energetic ion bombardment. Secondly, there is a formation of a low binding energy shoulder. This shoulder is centred at 98.7-99.3 eV, and is thus consistent with $\mathrm{Si}$ in the elemental state [61]. The second feature is more prominent for the spectra attained after sputter-etching with higher ion energies. The changes, compared to the pristine surface (green dashed spectra), are minor and almost non-existent in the spectra attained after etching with $200 \mathrm{eV} \mathrm{Ar}^{+}$.

\subsubsection{Al-Ge-N - Ge $2 p$ and $3 d$ core level spectra}

In contrast to the Al-Si-N system, the analogous Al-Ge-N system with its lower thermodynamic stability, exhibits large changes for the material subjected to high energy $\mathrm{Ar}^{+}$bombardment, as evidenced by the Ge core level spectra (Fig. 4). The pristine peak at higher binding energy $(1219.2 \mathrm{eV}$ and $31.4 \mathrm{eV}$ for $\mathrm{Ge} 2 \mathrm{p}_{3 / 2}$ and $\mathrm{Ge} 3 \mathrm{~d}$ peaks, respectively, typical for Ge bonded to $\mathrm{N}$ ) gradually decreases in intensity at higher sputter energies, while a low binding energy feature increases and gradually shifts to a position in agreement with elemental $\mathrm{Ge}(1217.0 \mathrm{eV}$ and $29.2 \mathrm{eV}$, respectively). For the highest alloying content and ion energies $(4 \mathrm{keV})$ the $\mathrm{Ge}$ in the material appears completely reduced to the metallic state.

It is worthwhile noting that Ge provides two core level lines within the range accessible for $\mathrm{Al} \mathrm{K \alpha}$ excitation: the $3 \mathrm{~d}$-line at a binding energy of ca $30 \mathrm{eV}$, and the $2 \mathrm{p}$ lines at ca $1218 \mathrm{eV}$. The photoelectrons have different kinetic energy and therefore different escape depths, $\sim 18 \AA$ for Ge $2 p$ and $\sim 63 \AA$ for $\mathrm{Ge} 3 \mathrm{~d}$ photoelectrons $[59,60]$. This gives rise to a distinct difference observed in the top and bottom spectra shown in Fig. $4 \mathrm{a}$ and b: Namely that the Ge $3 \mathrm{~d}$ spectra, originating from larger depth, show less damage. This is especially clear for the spectra obtained after etching with $1 \mathrm{keV} \mathrm{Ar}^{+}$. These observations can be understood by considering the depth at which the impinging $\mathrm{Ar}^{+}$ions lose their energy, which were simulated using the SRIM 2013 software. Fig. 5 shows the calculated energy loss of $\mathrm{Ar}^{+}$ions of different energy as a function of depth. As can be seen, the $200 \mathrm{eV} \mathrm{Ar}^{+}$lose practically all their energy (90\%) within $10 \AA$, and the $1 \mathrm{keV}$ and $4 \mathrm{keV}$ ions lose their energy within $22 \AA$ and $53 \AA$, respectively. It is thus clear that in the case of low energy $\mathrm{Ar}^{+}$bombardment the photoelectrons from the $3 \mathrm{~d}$ orbitals to a large extent originate from pristine material, below the damaged region, thus explaining the appearance of two rather distinct contributions of different intensity for $\mathrm{Ge} 2 \mathrm{p}$ and $\mathrm{Ge} 3 \mathrm{~d}$ spectral regions.

\subsubsection{Al-Sn-N - Sn 3d core level spectra}

For the Al-Sn-N material the alloying element (i.e. Sn) core levels exhibit large changes when subjected to $\mathrm{Ar}^{+}$ion bombardment, see Fig. 6 . As for the Al-Ge-N coatings, the observed damage consists of a gradual metallisation of the Sn core level as the energy of the $\mathrm{Ar}^{+}$is increased: the $\mathrm{Sn}$ $3 \mathrm{~d}_{5 / 2}$ peak transforms from a symmetrical peak at $486.3 \mathrm{eV}$ (consistent with $\mathrm{Sn}$ in a nitride environment) to an asymmetrical peak at $484.2 \mathrm{eV}$ (consistent with metallic $\mathrm{Sn}$ ). Considering that the other observed peaks from the same sample ( $\mathrm{Al} 2 \mathrm{p}, \mathrm{N}$ 1s and valence band, see Fig. 1, Fig. 2 and Fig. 9) are not shifting, the observed shift for Sn $3 d$ must be due to a change in chemical environment, not charging. The sample with higher alloying content is more affected by the bombardment, and almost no contribution from tin nitride is visible after $4 \mathrm{keV} \mathrm{Ar}^{+}$. However, for both high and low $\mathrm{Sn}$ concentrations the fraction of reduced Sn (artefacts as defined in the following section 4.2.5) in the spectra obtained after sputter-etching with $200 \mathrm{eV} \mathrm{Ar}^{+}$is limited.

\subsubsection{Quantification of sputter damage}

For the core level spectra (Si 2p, Sn 3d and Ge 3d) considered above, the extent of sputter-damage can be estimated via peak fitting. An example using the $\mathrm{Sn} 3 \mathrm{~d}$ spectrum from the low Sn-content sample after sputter-etching with $1 \mathrm{keV} \mathrm{Ar}^{+}$is shown in Fig. 7. Peak fitting was performed by using two peaks: one with fixed position, shape and width according to the pristine spectra; and one peak with fixed shape and width according to a best-possible fit to the most damaged sample. Fits were made on the spectra obtained after ion bombardment of varying energies by changing the intensity of these two contributions and also letting the position of the damage-peak vary. As evidenced by the difference spectrum (experimental - peak sum) in Fig. 7, this simple procedure does not give a perfect fit, but is sufficient to make an estimate of the extent of artefact formation. In the case shown, $60 \%$ of the signal originates from sputter-induced artefacts. A more detailed analysis would include more contributions 
and give better fits. This would perhaps also give additional information on the nature of the damaged material, but as this would include substantial uncertainties and is not the focus of the present study. Thus, the simpler approach which is sufficient to discuss trends in sputter damage is used.

Similar fits were conducted for all ternary samples (in the case of Al-Si-N, also the pristine peaks were allowed to shift by a small amount). The results of curve fittings are presented in Fig. 8, where the relative amount of artefact signal is plotted against $\mathrm{Ar}^{+}$ion energy, and Error! Reference source not found. Table 4 where additional details are provided. There are clear trends with respect to ion energy, alloying element and alloying concentration: The amount of sputter-damage increases with increased ion energy and alloying concentration, and also downward in group 14. The latter clearly correlates with the bond strength $\mathrm{A}-\mathrm{N}(\mathrm{A}=\mathrm{Si}, \mathrm{Ge}, \mathrm{Sn})$, as well as increasing mass difference in the samples. The information depth of the peaks used in damage evaluation are similar, varying between $4.7 \mathrm{~nm}(\mathrm{Sn} 3 \mathrm{~d})$ and $6.3 \mathrm{~nm}(\mathrm{Ge} \mathrm{3p})$, and thus allow for a valid comparison.

\subsubsection{Valence band spectra}

The valence band spectra reflect the chemical bonding of a material, since the energy of chemical bonds are of the magnitude of the observed binding energy range, i.e. 0 to $20 \mathrm{eV}$. Clear changes are observed for all samples after different ion bombardments, as shown in Fig. 9. In contrast to the core level spectra described above, the valence band spectra of all samples in the present study are affected by $\mathrm{Ar}^{+}$ion etching, including the single phase AlN sample.

In agreement with core level spectra, the changes increases with ion energy and with increased alloying content. Two additional peaks appear at $23.0 \mathrm{and} / \mathrm{or} 9.2 \mathrm{eV}$ post ion bombardment. These can be attributed photoelectron peaks from $\operatorname{Ar} 3 \mathrm{~s}$ and $3 \mathrm{p}$, respectively [14, 62], thus showing $\mathrm{Ar}$ implantation. This is also confirmed by survey spectra taken after sputter-etching with $4 \mathrm{keV} \mathrm{Ar}^{+}$(not shown), which all show Ar $2 p$ peaks which were not present on the pristine surface.

Furthermore, there is also a clear tendency of increased intensity at the Fermi level. This is most notable for high-alloying content Al-Ge-N and Al-Sn-N samples and reflects the metallisation of the alloying element, as described above. This appearance of metallic states at the Fermi edge goes in parallel with the decrease of the bonding N 2p-metal 3d hybrid state at ca. $6 \mathrm{eV}$ for Al-Ge-N and ca. 5 $\mathrm{eV}$ for Al-Sn-N [44, 63]. Similar, although smaller artefacts are visible also for the Al-Si-N as well as the AlN samples at higher $\mathrm{Ar}^{+}$energies.

\subsection{Ex-situ experiments: removal of surface oxides with $\mathrm{Ar}_{\mathrm{n}}{ }^{+}$cluster ions}

A recently developed technique to sputter clean surfaces with minimal sample damage is the gas cluster ion source (GCIS) [40]. In order to compare this new technique to traditional argon ion sputtering, one sample from the same deposition as a previously investigated sample was selected. The selected sample was the Al-Sn-N-sample with high alloying content, i.e. the most sputter-sensitive sample in the present study, which had been exposed to atmosphere before analysis. This sample was analysed after removal of the surface oxide using an $\mathrm{Ar}_{\mathrm{n}}{ }^{+}$cluster ion source. As shown in Table 3, two settings were used: a smaller cluster with high energy $\left(\mathrm{Ar}_{1000}{ }^{+}, 20 \mathrm{keV}\right)$, and a larger cluster with low energy $\left(\mathrm{Ar}_{2000}{ }^{+}, 5 \mathrm{keV}\right)$. The obtained spectra are shown in Fig. 10 (solid lines) together with reference data from the in-situ experiments described above (dotted line). The spectra after etching with $5 \mathrm{keV}$ $\mathrm{Ar}_{2000}{ }^{+}$(blue curves in Fig. 10) are almost identical to the reference spectra. In contrast to the spectra recorded after etching with $200 \mathrm{eV}$ monoatomic $\mathrm{Ar}^{+}$, there is no visible low-energy shoulder in the $\mathrm{Sn}$ $3 \mathrm{~d}$ peak. There is although a small shift of the $\mathrm{Sn} 3 \mathrm{~d}$ peak to higher binding energies, which most likely is connected to that not all surface oxide has been removed (as stated above the oxygen signal was reduced to $35 \%$ by this sputter-etching). Also the valence band spectrum in the binding energy region up to $15 \mathrm{eV}$ is unaltered, compared to the in-situ reference. This shows that artefact-free spectra of the bulk can be obtained using $\mathrm{Ar}_{n}{ }^{+}$cluster etching. However, the spectra recorded after etching with $20 \mathrm{keV} \mathrm{Ar}{ }_{1000}{ }^{+}$(red curves in Fig. 10) are distinctly different from the in-situ reference spectra, and show large similarities to that observed for monoatomic $\mathrm{Ar}^{+}$ion beam with an energy of $4 \mathrm{keV}$. This shows that using Argon clusters and working with inappropriate settings (in this case. $\mathrm{Ar}_{1000}{ }^{+}, 20$ $\mathrm{keV}$ ) may cause damages as severe as monoatomic sources. It must although be noted that the tested sample is extremely sensitive to energetic ion radiation, and is thus an extreme test.

\section{Discussion}




\subsection{Observed damage by monoatomic etching}

The presented results using traditional monoatomic ions are in good agreement with literature (e.g. [18]), confirming that low energy monoatomic ions used for sputter-etching significantly decrease the amount of sample damage. Fig. 8 is remarkably similar to the data presented in reference [18], indicating a common mechanism for the observed damage. It is also important to note that for very low energy $\mathrm{Ar}^{+}(200 \mathrm{eV})$ the obtained spectra for even the most sputter-sensitive Al-Sn-N are almost artefact-free, and can thus be used for the analysis of ex-situ transferred material. Such measurements have also been performed by the authors, and presented in the publications focused on respective materials, see references [44-46]. No additional features were observed as an effect of using the sputter-etching to remove the surface oxide.

There are two principle reasons why the spectra obtained post monoatomic $200 \mathrm{eV} \mathrm{Ar}^{+}$bombardment show less damage. The first is connected to the depth to which the energy of the $\mathrm{Ar}^{+}$ions is deposited, in comparison to the information depth of the observed photoelectrons, i.e. to what extent the pristine material can be analysed. The second relates to the amount of energy deposited in the material during ion bombardment, i.e. the amount of energy which can cause damage.

The first of these two points is illustrated by the results in Fig. 4 where the different information depths of the Ge $3 \mathrm{~d}$ and $2 \mathrm{p}$ core levels ( 18 and $63 \AA$, respectively) and different penetration depths of the $\mathrm{Ar}^{+}$ions are presented. At lower ion beam energy the damaged zone is shallower, and at sufficiently low ion energies the information depth of the probed core levels ( $\mathrm{Si} 2 \mathrm{p}, \mathrm{Ge} 3 \mathrm{~d}$ and Sn 3d) will be large enough that the recorded signal will be mainly obtained from the pristine material below the damaged surface, hence significant pristine signal after etching with $200 \mathrm{eV} \mathrm{Ar}^{+}$ions.

The second point is illustrated by considering how much energy is deposited by the impinging ions. As previously illustrated in Fig. 5, the energy of each $\mathrm{Ar}^{+}$ion will be deposited within a certain depth. Normalizing the kinetic energy of each ion by this penetration depth will give a measure of how much energy is deposited per unit depth in the material. In Fig. 11a, the relative amount of sputter damage is plotted $v s$ the ion energy (E) per penetration depth (D), where D is taken from Table 3. The fraction of sputter damage rises close to linearity with $\mathrm{E} / \mathrm{D}$, with different gradients for the different samples. The slope of these linear relations is a measure of the sputter sensitivity (the information depth of the observed core levels are roughly the same: 47-63 $\AA$, and thus comparable). This illustrates that, despite the larger penetration depth of more energetic ions, the sputter damage scales directly with the depthnormalised energy of the $\mathrm{Ar}^{+}$ions; and explains why less damage is observed after using $200 \mathrm{eV}$ ions.

An alternative, macroscopic way of estimating the relative amount of deposited energy is to consider the total dose of ions (given by the beam current and sputtering time) and the volume of removed material (from sputter depth and ion beam raster area). This results in a measure of energy per volume $\left(\mathrm{eV} / \AA^{3}\right)$, see Table 3. If the fraction of sputter damage is plotted against this parameter, an almost identical plot to Fig. 11a is obtained (see Fig. 11b). Since sputter depth as well as area was kept constant the parameter of importance is the total dose of ions, which mainly depends on the sputter rate of each setting (itself a function of ion energy and current). Thus, despite a distinctly larger dose of ions for the lower kinetic energy settings, the amount of energy deposited per removed volume is greater for the higher kinetic energy settings, and scales directly to the amount of observed artefacts in the material.

\subsection{Comparison of etching by GCIB to monoatomic $\mathrm{Ar}^{+}$}

For researchers interested in the surface analysis of sputter-sensitive materials, the results presented in this investigation illustrate three important points connected with the use of GCIS:

a) The use of an Argon ion cluster source for etching can successfully be employed to obtain almost artefact-free spectra, also for sensitive inorganic materials. However, as clearly shown by the differences between the spectra in Fig. 10, the use of an ion cluster beam is no guarantee for artefact-free spectra. Using the appropriate cluster size and cluster energy is essential when analysing sputter-sensitive materials. Two extremes settings for the GCIS were investigated here, namely maximum and minimum energy per Ar atom. In-between there is a wide field of useful settings, illustrating the need for further studies to understand, which parameters are decisive for the observed material damage. 
b) In the case for the minimum setting used here, the average energy per atom for the $5 \mathrm{keV}$ $\mathrm{Ar}_{2000}{ }^{+}$amounts to $2.5 \mathrm{eV}$ (see Table 3), which is in the same order of magnitude as the formation enthalpy for the investigated nitrides (see Table 1 and Table 2). An increase to the maximum setting of $20 \mathrm{kV} \mathrm{Ar}{ }_{1000}^{+}$(20 eV/atom) causes damage to the very sputter-sensitive Al-Sn-N sample, despite the fact that almost artefact-free spectra are attained after etching with monoatomic $200 \mathrm{eV} \mathrm{Ar}^{+}$. This demonstrates that average energy per particle is not the solely determining parameter for sputter damage. The dose is seemingly also of importance, but also the impact collision mechanics of the $\mathrm{Ar}_{\mathrm{n}}^{+}$gas cluster should be considered, and as pointed out by Simpson et al.[7] the thermal spike that occurs upon impact [40] may play an important role in causing damage.

c) It must be stated that for performing conventional depth profiling experiments for inorganic materials with a layer thicknesses greater than $10 \mathrm{~nm}$ it is impractical to use cluster ion beam acceleration energies of less than $10 \mathrm{kV}$ due to the low sputter etch rate. The low energy cluster mode $\left(5 \mathrm{keV} \mathrm{Ar} 2000{ }^{+} \mathrm{kV}\right)$ is suitable for sputter cleaning thin oxide films, not so for thicker materials.

\subsection{Sputter sensitivity and thermodynamic stability}

Also from a materials point of view a few trends are worth noting. One is that sample damage occurs also on thermodynamically highly stable systems such as single phase AlN, see e.g. top spectra in Fig. 9 , where 1 and $4 \mathrm{keV} \mathrm{Ar}^{+}$cause small changes to the valence band. However, it is clear that this sample is least affected in the present study. From Fig. 8 it is clear that the amount of damage sustained by the samples is correlated to the concentration of the alloying element. This can be illustrated by plotting the relative amount of sputter damage in the XPS core level spectra as a function of the weighted average of the standard enthalpy of formation (see Table 2) for the respective sample, as shown in Fig. 12. For the samples in the present study the trends are clear: The enthalpy of formation of the material determines whether sputter damage occurs and the ion energy largely determines to what degree sputter damage occurs. The spread of the data points is large, probably due to the rough estimation of the formation enthalpy and possibly due to errors in estimating the amount of damage (c.f. Fig. 7 and section 4.2.5). The threshold for substantial damage seems to be at a formation enthalpy of $-1.25 \mathrm{~V} /$ atom $(\sim-120 \mathrm{~kJ} / \mathrm{mol}$ atoms $)$.

Similar trends as those observed in the present work have been seen previously; the early studies of Christie et al. [24] demonstrated that for group 2 and 14 metal carbonates, sulphates and nitrates the observed damage due to a monoatomic $\mathrm{Ar}^{+}$ion beam could be directly correlated to the free energies of formation: significant damage (using a $3 \mathrm{keV} \mathrm{Ar}{ }^{+}$beam) occurred for salts with formation enthalpies between 0.5 and $1.6 \mathrm{eV} /$ atom $(50-153 \mathrm{~kJ} / \mathrm{mol}$ atoms), however salts with formations energies of ca $2.5 \mathrm{eV} /$ atom $(240 \mathrm{~kJ} / \mathrm{mol}$ atoms $)$ sustain much less damage.

Since the cluster ion experiments were only conducted on a single sample, the above discussed trends cannot be confirmed for gas cluster ion sputtering using the present data. However, Barlow et al. [41] investigated a number of binary semiconductor compounds using sputter-etching with an $\operatorname{Ar}_{1000}{ }^{+}$ source, and found that one compound (InAs) was much more sensitive to damage than the other compounds ( $\mathrm{CdTe}, \mathrm{GaAs}, \mathrm{GaP}, \mathrm{ZnSe}$ and $\mathrm{Hf}_{2}$ ). The damage could (as here) be avoided by lowering the energy of cluster beam, from 6 to $2 \mathrm{keV}$. Not explicitly considered by Barlow et al. was the standard energy of formation for the studied compounds. It is although interesting to note that InAs has the lowest $\Delta_{\mathrm{f}} \mathrm{H}^{\circ}$ of the studied compounds with $-58 \mathrm{~kJ} / \mathrm{mol}(\sim-0.6 \mathrm{eV} /$ formula unit), with the other compounds ranging from $-71 \mathrm{~kJ} / \mathrm{mol}(\mathrm{GaAs})$ to $-1145 \mathrm{~kJ} / \mathrm{mol}\left(\mathrm{HfO}_{2}\right)$ [48]. This thus fits with the trends observed in the present study with a threshold value for damage to occur (as the difference in formation energy between InAs and GaAs is small), but with a lower threshold value $(\sim 0.35 \mathrm{eV} /$ atom $)$ which is consistent with the differences in damage mechanisms for monoatomic and cluster ion sputter-etching.

For the present studied AlN-based solid solutions and nanocomposites, the stability is strongly dependent on the weaker nitride bond, and the observed damage is reduction of the weaker nitrideforming element (i.e. Si, Ge and $\mathrm{Sn}$ ). This suggests that the damage that occurs is preferential sputtering of the $\mathrm{N}$ atoms bonded to the weaker nitride forming metal (or semi-metal), leading to a reduction of this element. This is supported by the position and shape of the damage peaks in the core levels (see Fig. 1 through 4 and 6.), the increase of intensity at the Fermi level (see valence band 
spectra in Fig. 9), as well as the narrowing of the N1s peak, and the depletion of nitrogen in the samples upon sputter etching.

\subsection{Limits to acquisition of artefact-free surface information}

Without knowing a priori the sputter sensitivity of a material it is not possible to know the extent of artefact formation after a sputter cleaning. By comparing spectra obtained after exposure to different sputter conditions one can obtain information on the form of artefacts produced. The only way of knowing if spectra are artefact-free, is the comparison to an unexposed reference samples.

In the present work in-vacuo transfer was conducted to obtain reference spectra. Such a procedure requires customised equipment (vacuum transfer system and adapted deposition and XPS systems). Despite such efforts, the pristine surface may not be representative of the bulk of the material, as during growth many materials exhibit varying degrees of surface segregation, which means that e.g. one element may be over-represented in the surface near region. Also the approach using a capping layer to protect the surface suffers from the same issue, but it also puts extreme demands on the capping layer - it must be dense enough to hinder oxygen to reach the material underneath, and at the same time thin enough to be electron transparent for the photoelectrons that are analysed.

HAXPES has been used to obtain reference spectra without sputter cleaning, e.g. [15, 18]. This method also requires specialised equipment (a customized XPS system, or a dedicated beamline at a synchrotron facility) and also has the inherent problem that spectra will always contain information from the surface. Difference spectra between surface sensitive and more depth sensitive spectra is a way to counteract this, but such a procedure also adds to the general uncertainties, and the possibility that the near-surface region is not representative of the bulk is still an issue. To be aware of these issues connected to the reference methods is important in order not to over-interpret results in one direction or the other.

\section{Summarising remarks}

The present study demonstrates that sputter artefacts are an unwanted reality and need to be considered when using sputter-etching to gain access to the bulk of a material e.g. via performing sputter depth profiling to analyse different layers. It has also been demonstrated that an Ar gas cluster ion source can be used to obtain artefact-free spectra after etching, even for highly sensitive (inorganic) materials. However, using appropriate cluster energy and size is essential to obtain such results. To a large extent artefacts can also be avoided using very low energy (i.e. $200 \mathrm{eV}$ ) monoatomic ion beams, but at the cost of etching speed. In any case analysis must be carried out with an awareness of the possible artefacts which can be created. It has been shown for the case of AlN that also the chemical states of single-phase, thermodynamically stable materials can be affected of high energy $(4 \mathrm{keV})$ ions. Furthermore it has been shown that the enthalpy of formation of the studied materials is the determining factor for the materials sensitivity to sputter-damage. For monoatomic $\mathrm{Ar}$ etching of AlN-based materials a threshold value seems to be present at about $-1.25 \mathrm{eV} /$ atom $(\sim-120$ $\mathrm{kJ} / \mathrm{mol}$ atoms). A comparison to literature although makes it plausible that similar values are applicable also to further material systems.

\section{Acknowledgements}

Funding: This work was supported by the Swedish research council (VR) [grant numbers 623-2010604 and 623-2013-69]; "Stiftelsen Bengt Lundqvist Minne"; Uppsala university; and Empa.

\section{References}

[1] S. Hofmann, Auger- and X-Ray Photoelectron Spectroscopy in Materials Science, in, SpringerVerlag Berlin Heidelberg, 2013.

[2] S. Oswald, W. Brückner, XPS depth profile analysis of non-stoichiometric NiO films, Surf. Interface Anal., 36 (2004) 17-22. DOI: http://dx.doi.org/10.1002/sia.1640.

[3] R. Steinberger, J. Walter, T. Greunz, J. Duchoslav, M. Arndt, S. Molodtsov, D.C. Meyer, D. Stifter, XPS study of the effects of long-term $\mathrm{Ar}^{+}$ion and Ar cluster sputtering on the chemical 
degradation of hydrozincite and iron oxide, Corros. Sci., 99 (2015) 66-75. DOI: http://dx.doi.org/10.1016/j.corsci.2015.06.019.

[4] F.Y. Xie, L. Gong, X. Liu, Y.T. Tao, W.H. Zhang, S.H. Chen, H. Meng, J. Chen, XPS studies on surface reduction of tungsten oxide nanowire film by $\mathrm{Ar}^{+}$bombardment, J. Electron.

Spectrosc. Relat. Phenom., 185 (2012) 112-118. DOI:

http://dx.doi.org/10.1016/j.elspec.2012.01.004.

[5] N.V. Alov, XPS study of $\mathrm{MoO}_{3}$ and $\mathrm{WO}_{3}$ oxide surface modification by low-energy $\mathrm{Ar}^{+}$ion bombardment, physica status solidi (c), 12 (2015) 263-266. DOI:

http://dx.doi.org/10.1002/pssc.201400108.

[6] M. Anwar, C.A. Hogarth, G.A. Khan, R. Bulpett, X-ray photoelectron spectroscopic (XPS) investigations of etching and annealing effects on thin films of $\mathrm{MoO}_{3}$, Spectrochimica Acta Part B: Atomic Spectroscopy, 44 (1989) 789-793. DOI: http://dx.doi.org/10.1016/05848547(89)80077-1.

[7] R. Simpson, R.G. White, J.F. Watts, M.A. Baker, XPS investigation of monatomic and cluster argon ion sputtering of tantalum pentoxide, Appl. Surf. Sci., 405 (2017) 79-87. DOI: http://dx.doi.org/10.1016/j.apsusc.2017.02.006.

[8] J.D.P. Counsell, A.J. Roberts, W. Boxford, C. Moffitt, K. Takahashi, Reduced Preferential Sputtering of $\mathrm{TiO}_{2}$ using Massive Argon Clusters, Journal of Surface Analysis, 20 (2014) 211215.

http://www.sasj.jp/JSA/CONTENTS/vol.20 3/Vol.20\%20No.3/13 Paper Counsell r1.pdf.

[9] M. Petravic, P.N.K. Deenapanray, V.A. Coleman, K.-j. Kim, B. Kim, G. Li, Core-level photoemission and near-edge x-ray absorption fine-structure studies of GaN surface under lowenergy ion bombardment, J. Appl. Phys., 95 (2004) 5487-5493. DOI:

http://dx.doi.org/10.1063/1.1707232.

[10] R. Peter, A. Bozanic, M. Petravic, Y. Chen, L.-J. Fan, Y.-W. Yang, Formation of defects in boron nitride by low energy ion bombardment, J. Appl. Phys., 106 (2009) 083523. DOI: doi:http://dx.doi.org/10.1063/1.3253576.

[11] G.L. Fisher, M. Dickinson, S.R. Bryan, J. Moulder, C60 sputtering of organics: A study using TOF-SIMS, XPS and nanoindentation, Appl. Surf. Sci., 255 (2008) 819-823. DOI: http://doi.org/10.1016/j.apsusc.2008.05.182.

[12] T. Miyayama, N. Sanada, M. Suzuki, J.S. Hammond, S.-Q.D. Si, A. Takahara, X-ray photoelectron spectroscopy study of polyimide thin films with Ar cluster ion depth profiling, Journal of Vacuum Science \& Technology A, 28 (2010) L1-L4. DOI: http://dx.doi.org/10.1116/1.3336242.

[13] P. Ahlberg, F.O.L. Johansson, Z.B. Zhang, U. Jansson, S.L. Zhang, A. Lindblad, T. Nyberg, Defect formation in graphene during low-energy ion bombardment, APL Materials, 4 (2016) 046104. DOI: http://doi.org/10.1063/1.4945587.

[14] E. Walker, C.P. Lund, P. Jennings, J.C.L. Cornish, C. Klauber, G. Hefter, Noble gas ion effects on the XPS valence band spectra of silicon, Appl. Surf. Sci., 222 (2004) 13-16. DOI: http://dx.doi.org/10.1016/j.apsusc.2003.08.018.

[15] J. Sundberg, R. Lindblad, M. Gorgoi, H. Rensmo, U. Jansson, A. Lindblad, Understanding the effects of sputter damage in W-S thin films by HAXPES, Appl. Surf. Sci., 305 (2014) 203-213. DOI: http://dx.doi.org/10.1016/j.apsusc.2014.03.038.

[16] M.A. Baker, R. Gilmore, C. Lenardi, W. Gissler, XPS investigation of preferential sputtering of $\mathrm{S}$ from $\mathrm{MoS}_{2}$ and determination of $\mathrm{MoS}_{\mathrm{x}}$ stoichiometry from Mo and S peak positions, Appl. Surf. Sci., 150 (1999) 255-262. DOI: http://doi.org/10.1016/S0169-4332(99)00253-6.

[17] A. Santoni, F. Rondino, C. Malerba, M. Valentini, A. Mittiga, Electronic structure of $\mathrm{Ar}^{+}$ionsputtered thin-film $\mathrm{MoS}_{2}$ : A XPS and IPES study, Appl. Surf. Sci., 392 (2017) 795-800. DOI: http://doi.org/10.1016/j.apsusc.2016.09.007.

[18] E. Lewin, M. Gorgoi, F. Schäfers, S. Svensson, U. Jansson, Influence of sputter damage on the XPS analysis of metastable nanocomposite coatings, Surf. Coat. Technol., 204 (2009) 455-462. DOI: http://dx.doi.org/10.1016/j.surfcoat.2009.08.006.

[19] O. Tengstrand, N. Nedfors, M. Andersson, J. Lu, U. Jansson, A. Flink, P. Eklund, L. Hultman, Model for electron-beam-induced crystallization of amorphous $\mathrm{Me}-\mathrm{Si}-\mathrm{C}(\mathrm{Me}=\mathrm{Nb}$ or $\mathrm{Zr})$ thin films, J. Mater. Res., 29 (2014) 2854-2862. DOI: http://dx.doi.org/10.1557/jmr.2014.345.

[20] O. Tengstrand, N. Nedfors, M. Andersson, J. Lu, U. Jansson, A. Flink, P. Eklund, L. Hultman, Beam-induced crystallization of amorphous $\mathrm{Me}-\mathrm{Si}-\mathrm{C}(\mathrm{Me}=\mathrm{Nb}$ or $\mathrm{Zr})$ thin films during transmission electron microscopy, MRS Communications, 3 (2013) 151-155. DOI: http://dx.doi.org/10.1557/mrc.2013.31.

[21] V. Ignatova, D. Karpuzov, I. Chakarov, I. Katardjiev, Computer simulations of surface analysis using ion beams, Prog. Surf. Sci., 81 (2006) 247-335. DOI: http://doi.org/10.1016/j.progsurf.2006.03.003.

[22] J.B. Malherbe, S. Hofmann, J.M. Sanz, Preferential sputtering of oxides: A comparison of model predictions with experimental data, Appl. Surf. Sci., 27 (1986) 355-365. DOI: http://doi.org/10.1016/0169-4332(86)90139-X. 
[23] R. Holm, S. Storp, ESCA studies on changes in surface composition under ion bombardment, Applied physics, 12 (1977) 101-112. DOI: http://dx.doi.org/10.1007/bf00900076.

[24] A.B. Christie, J. Lee, I. Sutherland, J.M. Walls, An XPS study of ion-induced compositional changes with group II and group IV compounds, Applications of Surface Science, 15 (1983) 224-237. DOI: http://dx.doi.org/10.1016/0378-5963(83)90018-1.

[25] R. Kelly, I. Bertóti, A. Miotello, Composition changes in bombarded oxides and carbides: the distinction between ballistic, chemically guided, and chemically random behavior, Nucl. Instrum. Methods Phys. Res., Sect. B, 80-81 (1993) 1154-1163. DOI: http://doi.org/10.1016/0168-583X(93)90755-U.

[26] R. Kelly, On the problem of whether mass or chemical bonding is more important to bombardment-induced compositional changes in alloys and oxides, Surf. Sci., 100 (1980) 85 107. DOI: http://doi.org/10.1016/0039-6028(80)90446-X.

[27] S.F. Ho, S. Contarini, J.W. Rabalais, Ion-beam-induced chemical changes in the oxyanions $\left(\mathrm{MO}_{\mathrm{y}}{ }^{\mathrm{n}}\right)$ and oxides $\left(\mathrm{MO}_{\mathrm{x}}\right)$ where $\mathrm{M}=$ chromium, molybdenum, tungsten, vanadium, niobium and tantalum, The Journal of Physical Chemistry, 91 (1987) 4779-4788. DOI: http://doi.org/10.1021/j100302a027.

[28] D. Jaeger, J. Patscheider, A complete and self-consistent evaluation of XPS spectra of TiN, J. Electron. Spectrosc. Relat. Phenom., 185 (2012) 523-534. DOI: http://dx.doi.org/10.1016/j.elspec.2012.10.011.

[29] S. Malmgren, K. Ciosek, R. Lindblad, S. Plogmaker, J. Kühn, H. Rensmo, K. Edström, M. Hahlin, Consequences of air exposure on the lithiated graphite SEI, Electrochim. Acta, 105 (2013) 83-91. DOI: http://dx.doi.org/10.1016/j.electacta.2013.04.118.

[30] G. Greczynski, S. Mráz, L. Hultman, J.M. Schneider, Venting temperature determines surface chemistry of magnetron sputtered TiN films, Appl. Phys. Lett., 108 (2016) 041603. DOI: http://dx.doi.org/10.1063/1.4940974.

[31] G. Greczynski, D. Primetzhofer, L. Hultman, Reference binding energies of transition metal carbides by core-level x-ray photoelectron spectroscopy free from $\mathrm{Ar}^{+}$etching artefacts, Appl. Surf. Sci., 436 (2018) 102-110. DOI: http://doi.org/10.1016/j.apsusc.2017.11.264.

[32] M.A. Baker, S.J. Greaves, E. Wendler, V. Fox, A comparison of in situ polishing and ion beam sputtering as surface preparation methods for XPS analysis of PVD coatings, Thin Solid Films, 377-378 (2000) 473-477. DOI: http://doi.org/10.1016/S0040-6090(00)01272-4.

[33] K.-H. Ernst, B. Oral, On the chemistry at the Si,Ti-doped a-C:H/TiC interface, Thin Solid Films, 446 (2004) 72-77. DOI: http://doi.org/10.1016/S0040-6090(03)01324-5.

[34] C. Weiland, A.K. Rumaiz, P. Pianetta, J.C. Woicik, Recent applications of hard x-ray photoelectron spectroscopy, Journal of Vacuum Science \& Technology A, 34 (2016) 030801. DOI: doi:http://dx.doi.org/10.1116/1.4946046.

[35] K. Yates, R.H. West, Monochromatized Ag L $\alpha$ X-rays as a source for higher energy XPS, Surf. Interface Anal., 5 (1983) 133-138. DOI: http://dx.doi.org/10.1002/sia.740050402.

[36] M. Kobata, Iacute, Scaron, Igor, H. Iwai, H. Yamazui, H. Takahashi, M. Suzuki, H. Matsuda, H. Daimon, K. Kobayashi, Development of the Hard-X-ray Angle Resolved X-ray Photoemission Spectrometer for Laboratory Use, Anal. Sci., 26 (2010) 227-232. DOI: http://dx.doi.org/10.2116/analsci.26.227.

[37] M. Patt, S. Eriksson, HAXPES-Lab: The first laboratory based hard X-ray photoelectron spectroscopy system using a $9.25 \mathrm{keV}$ X-ray source, in: ECOSS, Grenoble, France, 2016.

[38] M. Gorgoi, N. Mårtensson, S. Svensson, HAXPES studies of solid materials for applications in energy and information technology using the HIKE facility at HZB-BESSY II, J. Electron. Spectrosc. Relat. Phenom., 200 (2015) 40-48. DOI: http://dx.doi.org/10.1016/j.elspec.2015.05.005.

[39] R. Grilli, R. Simpson, C.F. Mallinson, M.A. Baker, Comparison of $\mathrm{Ar}^{+}$Monoatomic and Cluster Ion Sputtering of $\mathrm{Ta}_{2} \mathrm{O}_{5}$ at Different Ion Energies, by XPS: Part 1 - Monoatomic Ions, Surf. Sci. Spectra, 21 (2014) 50-67. DOI: http://dx.doi.org/10.1116/11.20140701.

[40] I. Yamada, J. Matsuo, N. Toyoda, A. Kirkpatrick, Materials processing by gas cluster ion beams, Materials Science and Engineering: R: Reports, 34 (2001) 231-295. DOI: http://doi.org/10.1016/S0927-796X(01)00034-1.

[41] A.J. Barlow, J.F. Portoles, P.J. Cumpson, Observed damage during Argon gas cluster depth profiles of compound semiconductors, J. Appl. Phys., 116 (2014) 054908. DOI: http://dx.doi.org/10.1063/1.4892097.

[42] A. Pélisson, M. Parlinska-Wojtan, H.J. Hug, J. Patscheider, Microstructure and mechanical properties of Al-Si-N transparent hard coatings deposited by magnetron sputtering, Surface \& Coatings Technology, 202 (2007) 884-889. DOI:

http://dx.doi.org/10.1016/j.surfcoat.2007.05.094.

[43] A. Pélisson-Schecker, H.J. Hug, J. Patscheider, Morphology, microstructure evolution and optical properties of Al-Si-N nanocomposite coatings, Surf. Coat. Technol., 257 (2014) 114120. DOI: http://dx.doi.org/10.1016/j.surfcoat.2014.08.053. 
[44] E. Lewin, M. Parlinska-Wojtan, J. Patscheider, Nanocomposite Al-Ge-N thin films and their mechanical and optical properties, J. Mater. Chem., 22 (2012) 16761-16773. DOI: http://dx.doi.org/10.1039/c2jm32815a.

[45] E. Lewin, J. Patscheider, Structure and properties of sputter-deposited Al-Sn-N thin films, Journal of Alloys and Compounds, 682 (2016) 42-51. DOI: http://dx.doi.org/10.1016/j.jallcom.2016.04.278.

[46] E. Lewin, D. Loch, A. Montagne, A.P. Ehiasarian, J. Patscheider, Comparison of Al-Si-N nanocomposite coatings deposited by HIPIMS and DC magnetron sputtering, Surface \& Coatings Technology, 232 (2013) 680-689. DOI: http://dx.doi.org/10.1016/j.surfcoat.2013.06.076.

[47] A. Pélisson-Schecker, H.J. Hug, J. Patscheider, Complex phase compositions in nanostructured coatings as evidenced by photoelectron spectroscopy: The case of Al-Si-N hard coatings, J. Appl. Phys., 108 (2010) 023508. DOI: http://dx.doi.org/10.1063/1.3460099.

[48] G. Aylward, T. Findlay, SI chemical data, 4th edition ed., Jacaranda Wiley Ltd., Milton, Australia, 1998.

[49] J.-j. Liang, L. Topor, A. Navrotsky, M. Mitomo, Silicon nitride: Enthalpy of formation of the $\alpha$ and $\beta$-polymorphs and the effect of C and O impurities, J. Mater. Res., 14 (2011) 1959-1968. DOI: http://dx.doi.org/10.1557/JMR.1999.0264.

[50] D.A. Jaeger, PhD thesis, Interface Investigations on Titanium Nitride Bilayer Systems. EPFL, Lausanne, Switzerland, 2012 DOI: http://dx.doi.org/10.5075/epfl-thesis-5509.

[51] M.P. Seah, Summary of ISO/TC 201 Standard: VII ISO 15472:2001 - surface chemical analysis - X-ray photoelectron spectrometers - calibration of energy scales, Surf. Interface Anal., 31 (2001) 721-723. DOI: http://dx.doi.org/10.1002/sia.1076.

[52] I. Bertóti, Characterization of nitride coatings by XPS, Surf. Coat. Technol., 151-152 (2002) 194-203. DOI: http://dx.doi.org/10.1016/s0257-8972(01)01619-x.

[53] A. Pélisson-Schecker, H.J. Hug, J. Patscheider, Charge referencing issues in XPS of insulators as evidenced in the case of Al-Si-N thin films, Surf. Interface Anal., 44 (2012) 29-36. DOI: http://dx.doi.org/10.1002/sia.3765.

[54] P.E. Larson, M.A. Kelly, Surface charge neutralization of insulating samples in X-ray photoemission spectroscopy, J. Vac. Sci. Technol. A, 16 (1998) 3483-3489. DOI: http://dx.doi.org/10.1116/1.581507.

[55] A.R. Walker, S.C. Page, Charged particle energy analyzers, US 5286974, 1994

[56] R.W.M. Kwok. XPS Peak 4.1, 1999

[57] J.F. Ziegler. SRIM 2013, http://www.srim.org/, 2013

[58] J.F. Ziegler, Srim-2003, Nuclear Instruments \& Methods in Physics Research Section B-Beam Interactions with Materials and Atoms, 219 (2004) 1027-1036. DOI: http://dx.doi.org/10.1016/j.nimb.2004.01.208.

[59] S. Tougaard. QUASES, http://www.quases.com/, 2010

[60] S. Tanuma, C.J. Powell, D.R. Penn, Calculations of electron inelastic mean free paths. V. Data for 14 organic compounds over the 50-2000 eV range, Surf. Interface Anal., 21 (1994) 165-176. DOI: http://dx.doi.org/10.1002/sia.740210302.

[61] J.F. Moulder, W.F. Stickle, P.E. Sobol, K.D. Bomben, Handbook of X-ray Photoelectron Spectroscopy, Physical Electronics, Inc., Eden Prairie, Minnesota, USA, 1995.

[62] A. Thompson, I. Lindau, D. Attwood, Y. Liu, E. Gullikson, P. Pianetta, M. Howells, A. Robinson, K.-J. Kim, J. Scofield, J. Kirz, J. Underwood, J. Kortright, G. Williams, H. Winick, X-ray Data Booklet, Third ed., Lawrence Berkley National Laboratory, 2009.

[63] D. Comedi, A.R. Zanatta, I. Chambouleyron, F. Alvarez, Valence band structure of amorphous germanium-nitrogen alloys, AIP Conf. Proc., 378 (1996) 310-314. DOI: http://dx.doi.org/10.1063/1.51112. 


\section{Tables}

Table 1 Thermodynamic data for the group 14 nitrides. $\Delta_{\mathrm{f}} \mathrm{H}^{\circ}$ is the standard enthalpy of formation [48, 49]. In the second and third data columns normalisation has been done with respect to number of atoms in the respective compound.

\begin{tabular}{cccc} 
Compound & $\begin{array}{c}\Delta_{\mathrm{f}} \mathrm{H}^{\circ} \\
(\mathrm{kJ} / \mathrm{mol} \text { compound })\end{array}$ & $\begin{array}{c}\text { normalised } \Delta_{\mathrm{f}} \mathrm{H}^{\circ} \\
(\mathrm{kJ} / \mathrm{mol} \text { atoms })\end{array}$ & $\begin{array}{c}\text { normalised } \Delta_{\mathrm{f}} \mathrm{H}^{\circ} \\
(\mathrm{eV} / \text { atom })\end{array}$ \\
\hline $\mathrm{AlN}$ & -318 & -159 & -1.65 \\
$\mathrm{Si}_{3} \mathrm{~N}_{4}$ & -851 & -122 & -1.26 \\
$\mathrm{Ge}_{3} \mathrm{~N}_{4}$ & -63 & -9 & -0.09 \\
$\mathrm{SnN}_{\mathrm{x}}$ & $\mathrm{n} / \mathrm{a}$ & $\mathrm{n} / \mathrm{a}$ & $\mathrm{n} / \mathrm{a}$
\end{tabular}

Table 2 Summary of samples investigated in the present study. Compositions from XPS measurements, phase content from XRD and TEM, thickness from SEM. The average $\Delta_{\mathrm{f}} \mathrm{H}^{\circ}$ is is estimated from the standard energy of formation of the binary nitrides (see Table 1) and the elemental composition of respective sample.

\begin{tabular}{|c|c|c|c|c|c|c|c|c|}
\hline \multirow{2}{*}{ Sample } & \multicolumn{4}{|c|}{ Composition (at.\%) } & \multirow{2}{*}{ Microstructure } & \multirow{2}{*}{ Phase(s) } & \multirow{2}{*}{$\begin{array}{c}\text { Coating } \\
\text { thickness } \\
(\mathrm{nm})\end{array}$} & \multirow{2}{*}{$\begin{array}{c}\text { Average } \\
\Delta_{\mathrm{f}} \mathrm{H}^{\circ} \\
\text { (eV/ atom) }\end{array}$} \\
\hline & $\mathrm{Al}$ & $\mathrm{Si} / \mathrm{Ge} / \mathrm{Sn}$ & $\mathrm{N}$ & $\mathrm{O}$ & & & & \\
\hline AlN & 46 & 0 & 54 & $<<1$ & single phase & $\overline{\mathrm{AlN}}$ & $\sim 80$ & -1.65 \\
\hline Al-Si-N low [Si] & 34 & 11 & 55 & $<0.5$ & nanocomposite & $\mathrm{nc}-\left(\mathrm{Al}_{1-\mathrm{x}} \mathrm{Si}_{\mathrm{x}}\right) \mathrm{N} / \mathrm{a}-\mathrm{Si}_{3} \mathrm{~N}_{4}$ & $\sim 110$ & -1.44 \\
\hline Al-Si-N high [Si] & 25 & 20 & 55 & $<0.5$ & nanocomposite & nc- $\left(\mathrm{Al}_{1-\mathrm{x}} \mathrm{Si}_{\mathrm{x}}\right) \mathrm{N} / \mathrm{a}-\mathrm{Si}_{3} \mathrm{~N}_{4}$ & $\sim 140$ & -1.36 \\
\hline Al-Ge-N low [Ge] & 32 & 12 & 56 & $<0.5$ & single phase & $n c-\left(\mathrm{Al}_{1-\mathrm{x}} \mathrm{Ge}_{\mathrm{x}}\right) \mathrm{N}_{\mathrm{y}}$ & $\sim 170$ & -0.75 \\
\hline Al-Ge-N high [Ge] & 22 & 26 & 52 & $<0.5$ & nanocomposite & $n c-\left(\mathrm{Al}_{1-\mathrm{x}} \mathrm{Ge}_{\mathrm{x}}\right) \mathrm{N}_{\mathrm{y}} / \mathrm{a}-\mathrm{GeN}_{\mathrm{z}}$ & $\sim 270$ & -0.38 \\
\hline Al-Sn-N low [Sn] & 36 & 10 & 54 & $<0.5$ & single phase & $n c-\left(\mathrm{Al}_{1-\mathrm{x}} \mathrm{Sn}_{\mathrm{x}}\right) \mathrm{N}_{\mathrm{y}}$ & $\sim 130$ & -0.84 \\
\hline Al-Sn-N high [Sn] & 28 & 21 & 51 & $<0.5$ & single phase & $\mathrm{nc}-\left(\mathrm{Al}_{1-\mathrm{x}} \mathrm{Sn}_{\mathrm{x}}\right) \mathrm{N}_{\mathrm{y}}$ & $\sim 220$ & -0.45 \\
\hline
\end{tabular}

Table 3 Sputter-etching parameters used in the study with monoatomic $\mathrm{Ar}^{+}$conducted with a Physical electronics Quantum 2000 . Etching with polyatomic $\mathrm{Ar}_{n}{ }^{+}$-clusters conducted in a Kratos AXIS Supra spectrometer. Values of ion current are typical for respective instrument settings. Both relative dose and deposited energy is given per removed volume of material, thus compensating for both different sputter depth and area. D is the depth at which $90 \%$ of the energy of monoatomic species has been deposited according to SRIM simulations (c.f Fig. 8). "Sputter rates for argon cluster experiments are calibrated to $\mathrm{Ta}_{2} \mathrm{O}_{5}$ thin film standard

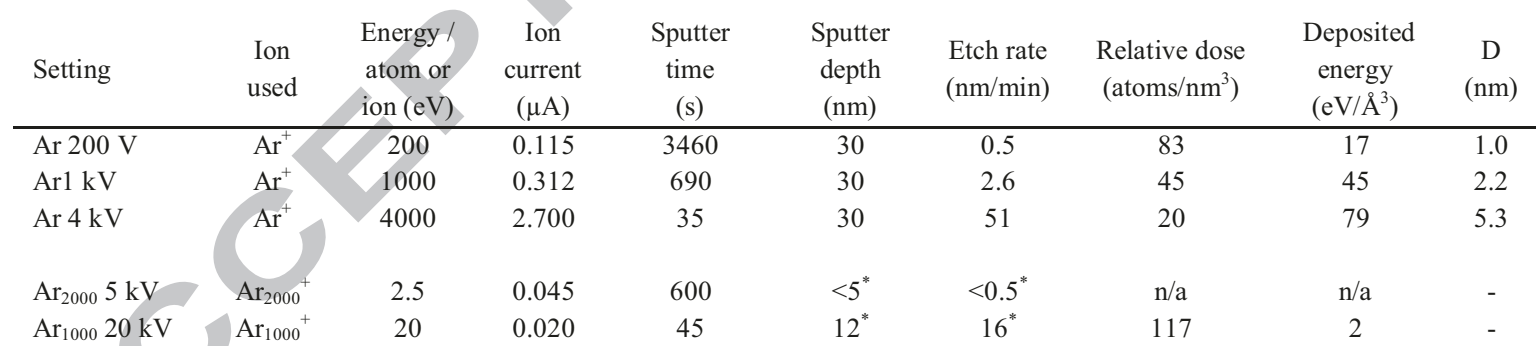

Table 4 Results of peak fittings for evaluation of relative amount of sputter-etching artefacts. For each fitted component $E_{B}$ specifies the peak position, fwhm the full width at half maximum, $\% \mathrm{~L}$ the Lorentzian contribution to the Voigt function, and asymmetry gives the tail strength and length parameters. Amount of artefacts refer to the relative intensity of the damage component compared to the entire peak intensity. The latter is also plotted in Fig. 8. An example of the peak fittings are shown in Fig. 7.

\begin{tabular}{|c|c|c|c|c|c|c|c|c|c|c|c|}
\hline \multirow[b]{2}{*}{ Sample } & \multirow[b]{2}{*}{ Peak } & \multicolumn{3}{|c|}{ Pristine component } & \multicolumn{4}{|c|}{ Damage component } & \multicolumn{3}{|c|}{ Amount of artefacts $(\%)$} \\
\hline & & $\mathrm{E}_{\mathrm{B}}(\mathrm{eV})$ & $\begin{array}{c}\text { fwhm } \\
(\mathrm{eV})\end{array}$ & $\% \mathrm{~L}$ & $\mathrm{E}_{\mathrm{B}}(\mathrm{eV})$ & $\begin{array}{c}\text { fwhm } \\
(\mathrm{eV})\end{array}$ & $\% \mathrm{~L}$ & asymmetry & $200 \mathrm{eV}$ & $1 \mathrm{keV}$ & $4 \mathrm{keV}$ \\
\hline Al-Si-N low [Si] & \multirow{2}{*}{ Si $2 p$} & $101.4-101.1$ & 1.9 & 0 & 98.7 & 1.6 & 20 & $\mathrm{n} / \mathrm{a}$ & 0 & 5 & 8 \\
\hline Al-Si-N high [Si] & & 101.2-100.9 & 1.7 & 0 & 99.3 & 2.2 & 20 & $\mathrm{n} / \mathrm{a}$ & 4 & 8 & 14 \\
\hline Al-Ge-N low [Ge] & \multirow{2}{*}{ Ge $3 d$} & 31.4 & 2.1 & 15 & $28.9-29.2$ & 2.0 & 7 & $0.8 / 15$ & 14 & 39 & 69 \\
\hline Al-Ge-N high [Ge] & & 31.4 & 1.7 & 15 & $29.6-29.2$ & 1.5 & 7 & $0.8 / 15$ & 19 & 60 & 82 \\
\hline Al-Sn-N low [Sn] & \multirow{2}{*}{$\mathrm{Sn} 3 \mathrm{~d} 5 / 2$} & 486.2 & 1.6 & 15 & $484.9-484.7$ & 1.4 & 30 & $0.3 / 50$ & 26 & 60 & 85 \\
\hline Al-Sn-N high [Sn] & & 486.3 & 1.5 & 15 & $485.1-484.6$ & 1.2 & 30 & $0.3 / 50$ & 27 & 71 & 95 \\
\hline
\end{tabular}




\section{Figure captions}

Fig. 1 XPS spectra of the A12p region from in-situ experiments of all samples. The four spectra per sample show spectra attained on the surface (green, dotted line), and after sputter-etching using $200 \mathrm{eV}$ (blue solid line), $1 \mathrm{keV}$ (yellow solid line) and $4 \mathrm{keV}$ (red solid line) $\mathrm{Ar}^{+}$to a depth of ca $30 \mathrm{~nm}$. (Colour online)

Fig. 2 XPS spectra of the N1s region from in-situ experiments of all samples. The four spectra per sample show spectra attained on the surface (green, dotted line), and after sputter-etching using $200 \mathrm{eV}$ (blue solid line), $1 \mathrm{keV}$ (yellow solid line) and $4 \mathrm{keV}$ (red solid line) $\mathrm{Ar}^{+}$to a depth of ca $30 \mathrm{~nm}$. (Colour online)

Fig. 3 XPS spectra of the Si2p region, from in-situ experiments. The four spectra per sample show spectra attained on the surface (green, dotted line), and after sputter-etching using $200 \mathrm{eV}$ (blue solid line), $1 \mathrm{keV}$ (yellow solid line) and $4 \mathrm{keV}$ (red solid line) $\mathrm{Ar}^{+}$to a depth of ca $30 \mathrm{~nm}$. (Colour online)

Fig. 4 XPS spectra of the Ge $2 \mathrm{p}_{3 / 2}$ (a) and Ge $3 \mathrm{~d}$ (b) regions, respectively, from in-situ experiments. The four spectra per sample show spectra attained on the surface (green, dotted line), and after sputter-etching using $200 \mathrm{eV}$ (blue solid line), $1 \mathrm{keV}$ (yellow solid line) and $4 \mathrm{keV}$ (red solid line) $\mathrm{Ar}^{+}$to a depth of ca30 $\mathrm{nm}$. (Colour online)

Fig. 5 Energy lost by impinging $\mathrm{Ar}^{+}$ions as a function of depth in the material, estimated by SRIM simulations. Different ion energies shown in colour: $200 \mathrm{eV}$ (blue), $1 \mathrm{keV}$ (yellow) and $4 \mathrm{keV}$ (red). Solid lines show loss at depth (left axis), and dashed lines show cumulative loss (right axis). Solid vertical lines mark the information depth (ID) of the Ge $2 p$ and Ge $3 p$ spectral regions. (Colour online)

Fig. 6 XPS spectra of the Sn3d region from in-situ experiments. The four spectra per sample show spectra attained on the surface (green, dotted line), and after sputter-etching using $200 \mathrm{eV}$ (blue solid line), $1 \mathrm{keV}$ (yellow solid line) and $4 \mathrm{keV}$ (red solid line) $\mathrm{Ar}^{+}$to a depth of ca $30 \mathrm{~nm}$. (Colour online)

Fig. 7 Peak-fitting of the Ge $3 \mathrm{~d}_{5 / 2}$ peak to estimate amount of sputter-damage artefacts. The sample is a low-alloying content AlSnN; the

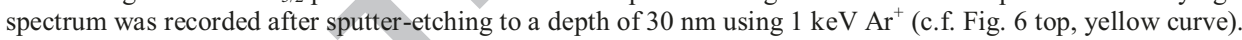

Fig. 8 Estimated amount of sputter-damage for all samples in the present study as a function of $\mathrm{Ar}^{+}$energy. The amount of sputterdamage is estimated by peak-fitting (c.f. Fig. 7) of the $\mathrm{Si} 2 \mathrm{p}$, Ge $3 \mathrm{~d}$ and $\mathrm{Sn} 3 \mathrm{~d} 5 / 2$ peak respectively. The information depth of these photoelectrons is between 5 and $6 \mathrm{~nm}$.

Fig. 9 XPS spectra of the valence region from in-situ experiments of all samples. The four spectra per sample show spectra attained on the surface (green, dotted line), and after sputter-etching using $200 \mathrm{eV}$ (blue solid line), $1 \mathrm{keV}$ (yellow solid line) and $4 \mathrm{keV}$ (red solid line) $\mathrm{Ar}^{+}$to a depth of ca $30 \mathrm{~nm}$. (Colour online)

Fig. 10 XPS spectra from ex-situ measurements of the high alloying content Al-Sn-N sample after removal of surface oxide with Ar ${ }_{n}^{+}$ cluster ions (solid lines). Reference spectra from in-situ experiments in another system are shown for comparison (dashed line). (Colour online)

Fig. 11 Estimated amount of sputter-damage for all samples in the present study as a function of ion energy per depth (a) or removed volume of material (b) The amount of sputter-damage is estimated by peak-fitting (c.f. Fig. 7) of the Si 2 p, Ge $3 \mathrm{~d}$ and $\mathrm{Sn} 3 \mathrm{~d} 5 / 2$ peak respectively. The information depth of these photoelectrons is between 5 and $6 \mathrm{~nm}$.

Fig. 12 Correlation between amount of sputter damage sustained by the samples, and the estimated standard enthalpy of formation for the ternary samples, see Table 2. Dashed lines are only intended as guides for the eye. 




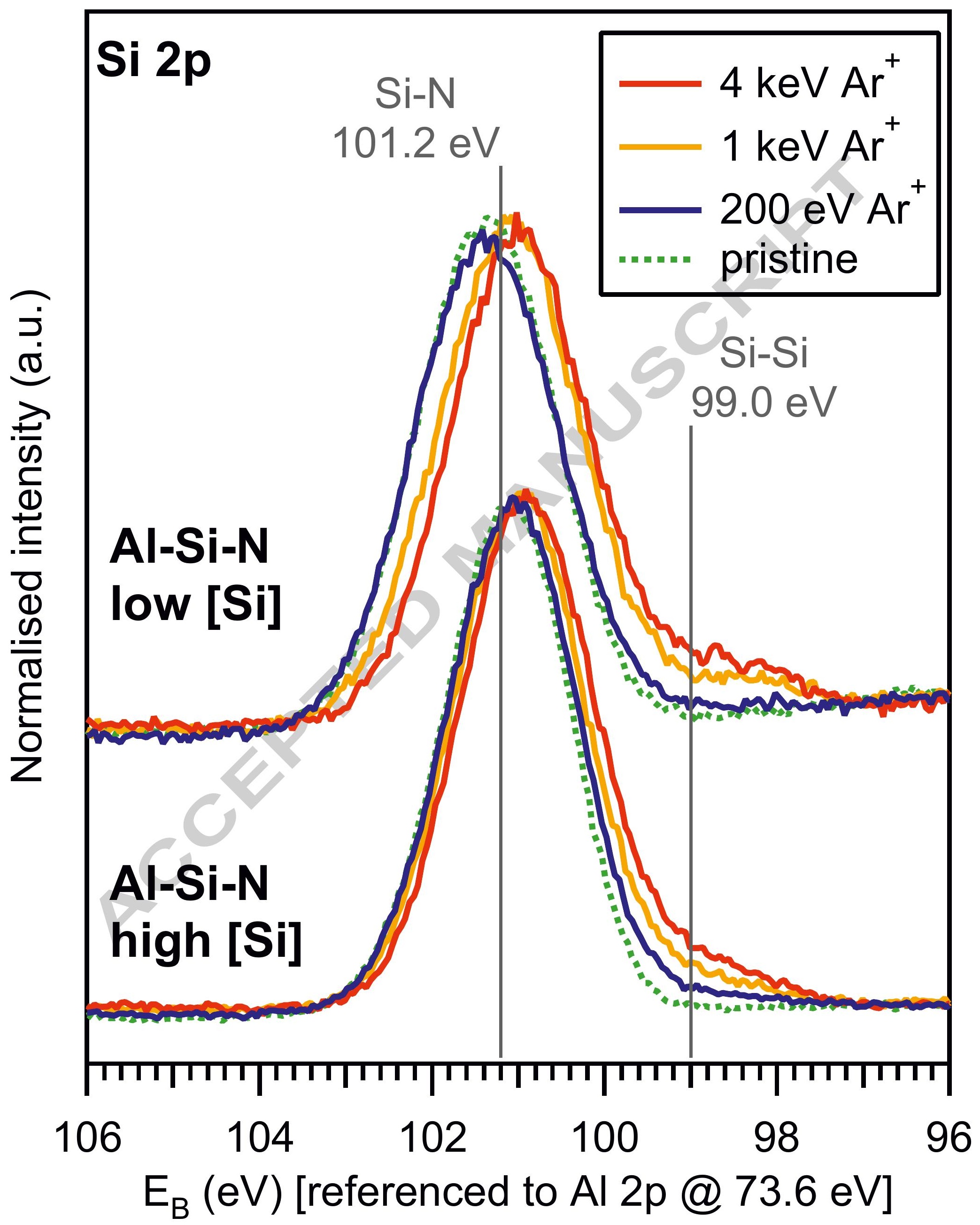




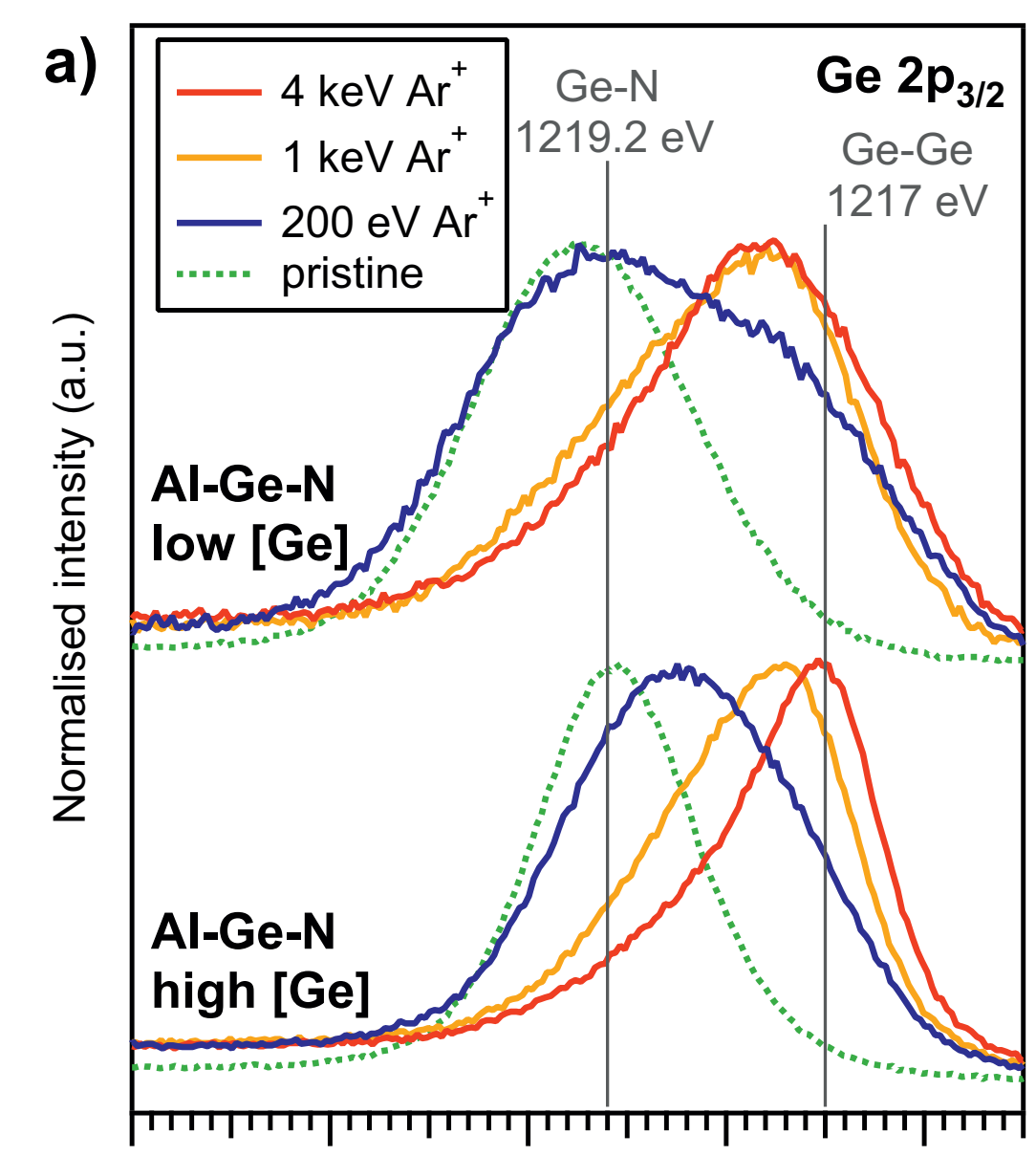

$\begin{array}{lllll}1224 & 1222 & 1220 & 1218 & 1216\end{array}$

$\mathrm{E}_{\mathrm{B}}(\mathrm{eV})$ [referenced to Al 2p @ $73.6 \mathrm{eV}$ ]

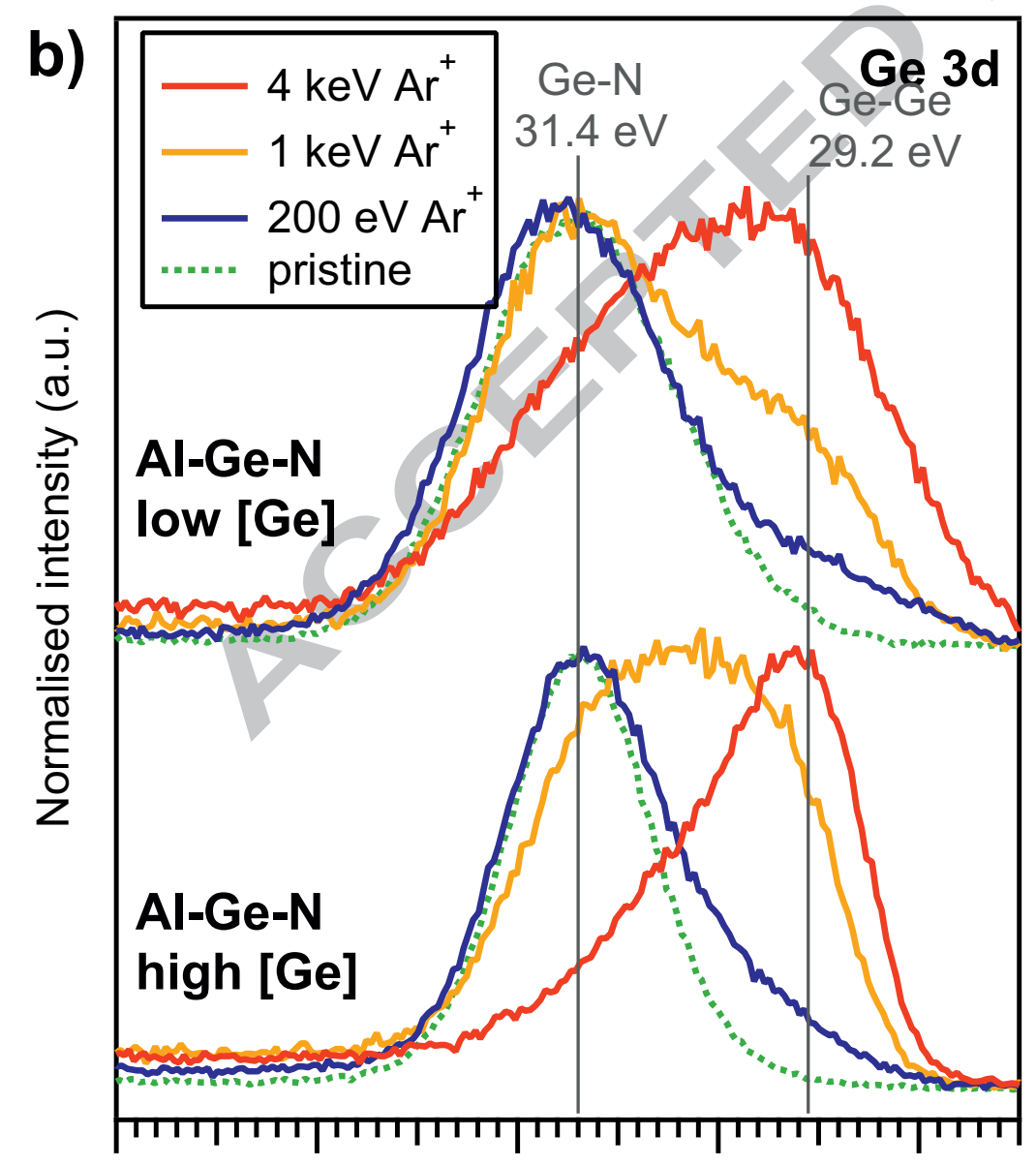

$\begin{array}{lllll}36 & 34 & 32 & 30 & 28\end{array}$

$\mathrm{E}_{\mathrm{B}}(\mathrm{eV})$ [referenced to Al 2p @73.6 eV] 


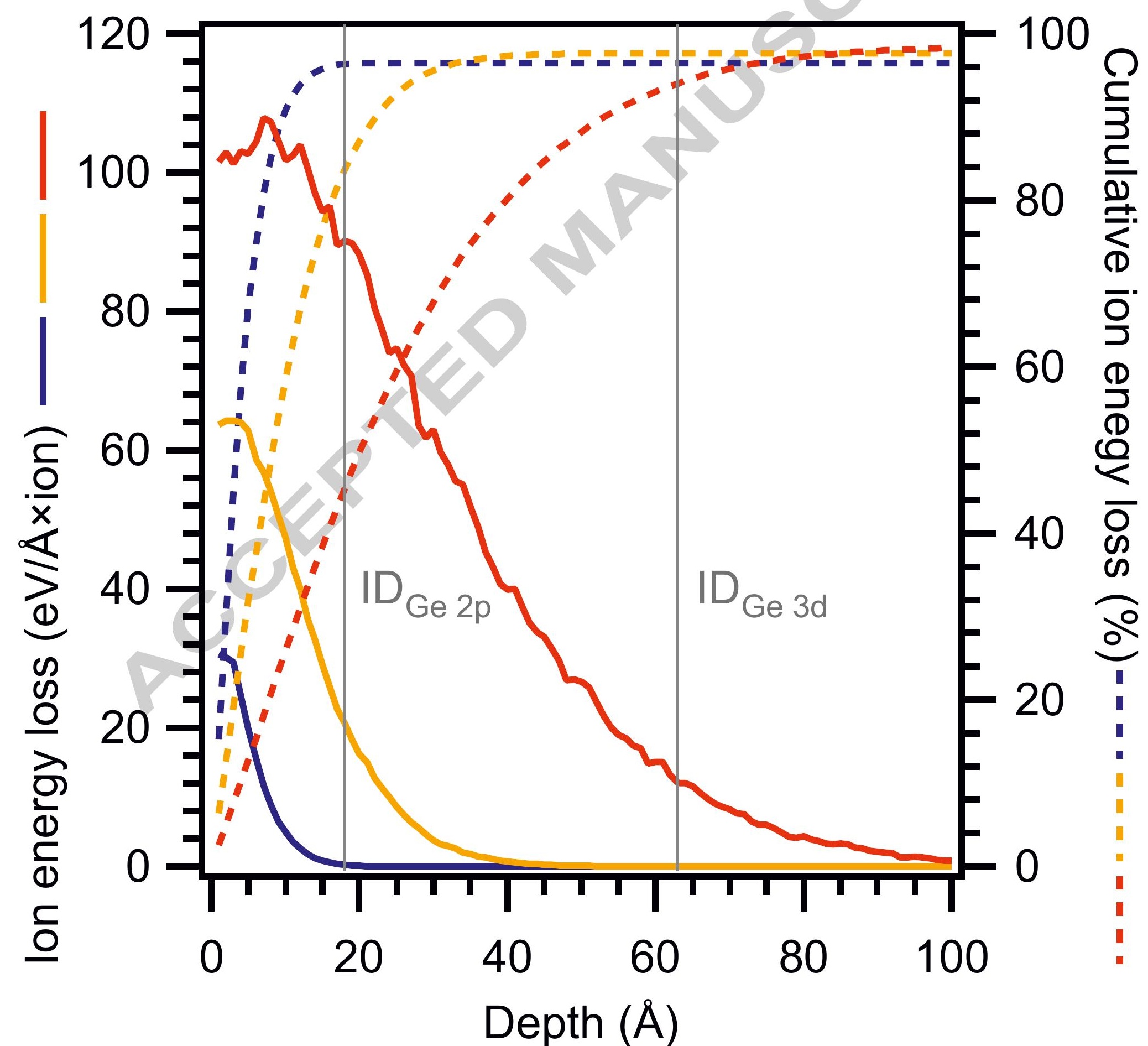




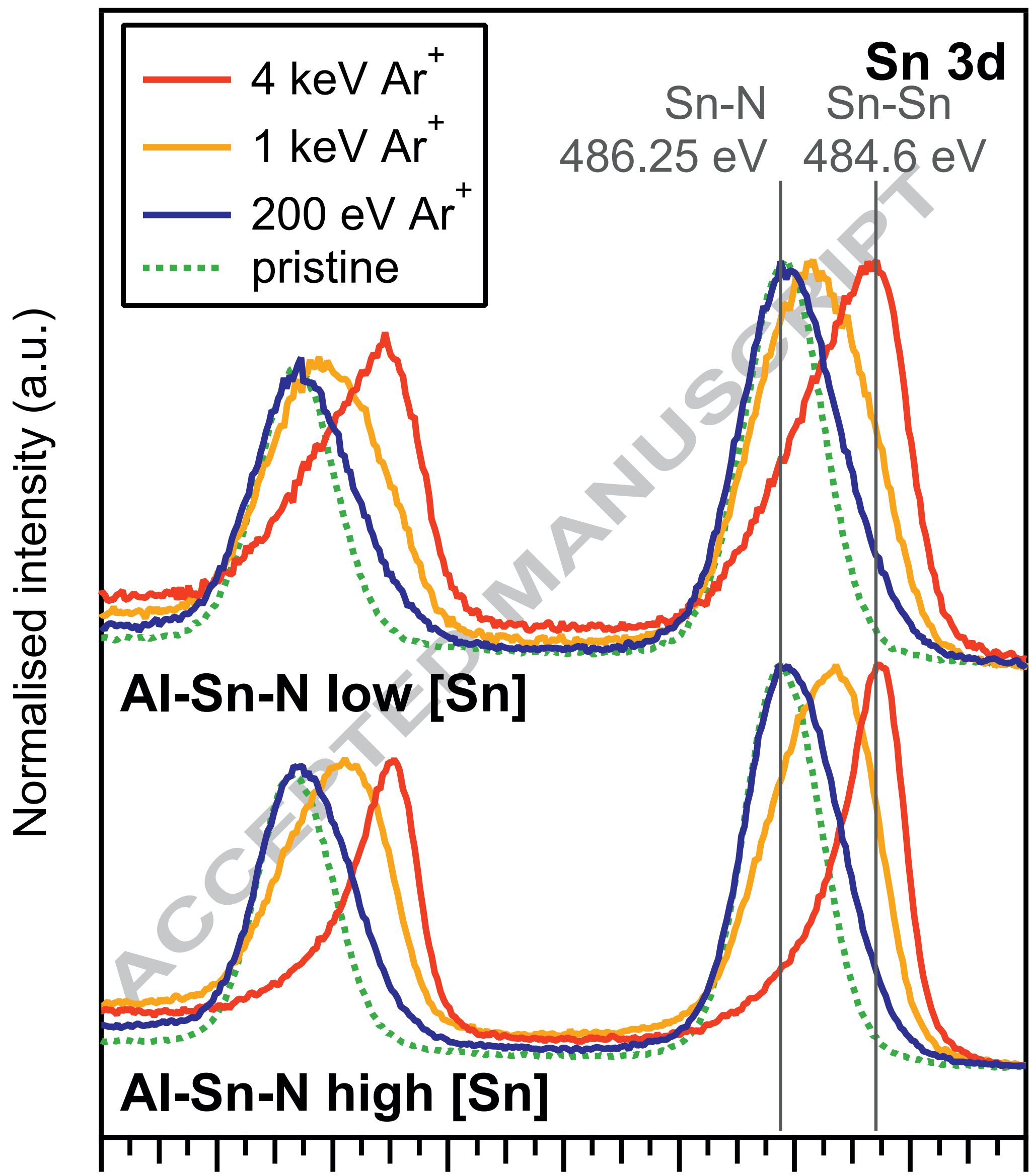

$\begin{array}{lllllllll}498 & 496 & 494 & 492 & 490 & 488 & 486 & 484 & 482\end{array}$ $\mathrm{E}_{\mathrm{B}}(\mathrm{eV})$ [referenced to $\left.\mathrm{Al} 2 \mathrm{p} @ 73.6 \mathrm{eV}\right]$ 


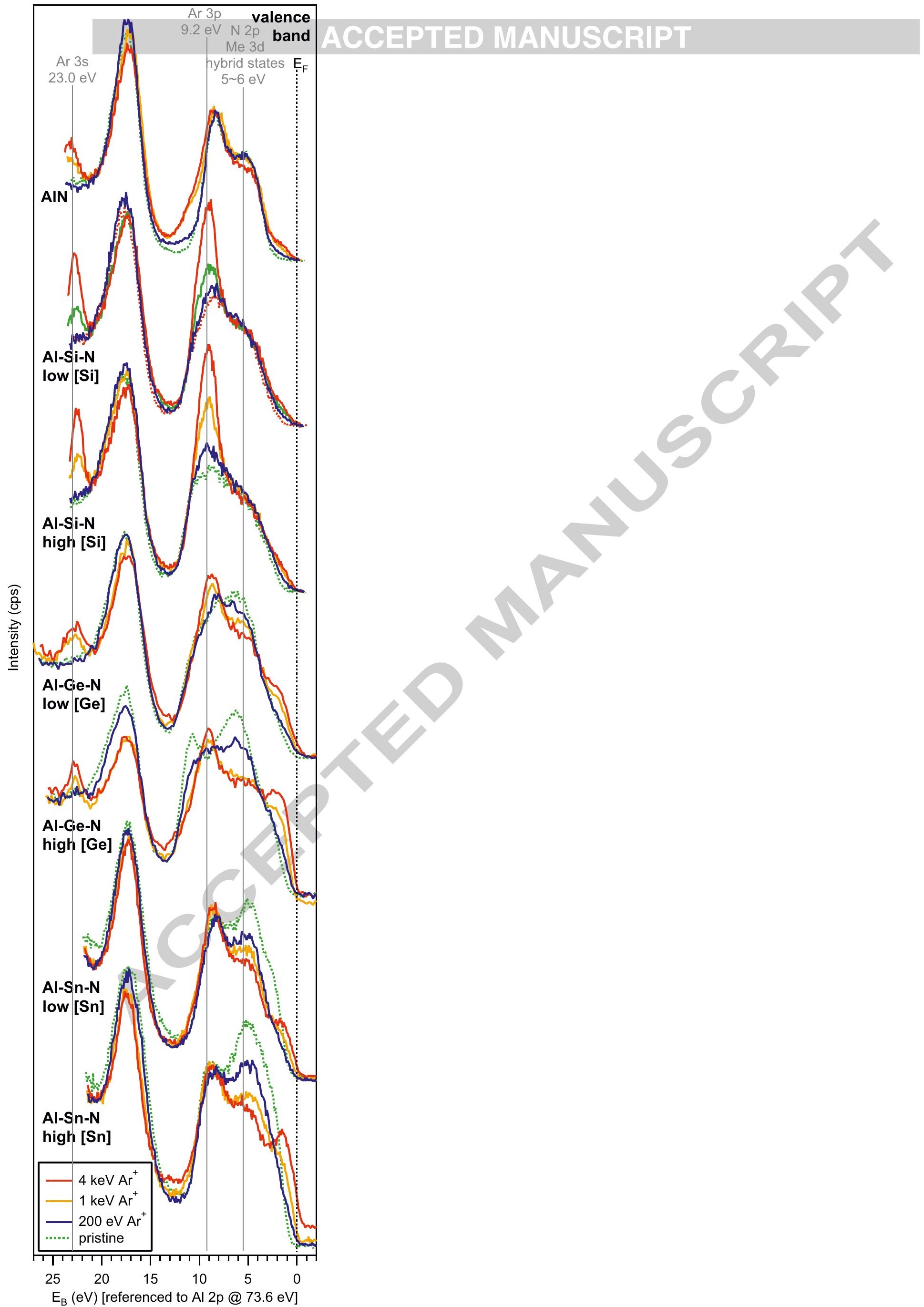




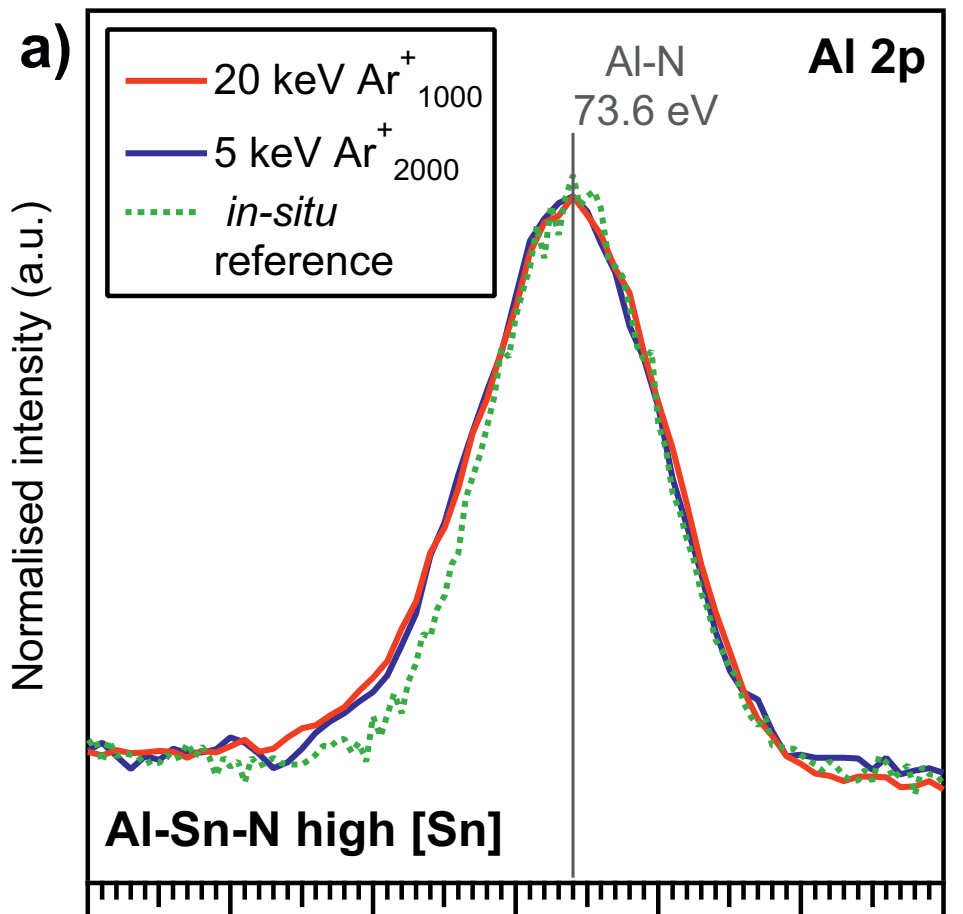

$\begin{array}{lllllll}77 & 76 & 75 & 74 & 73 & 72 & 71\end{array}$ $E_{B}(e V)$ [referenced to Al 2p @ 73.6 eV]

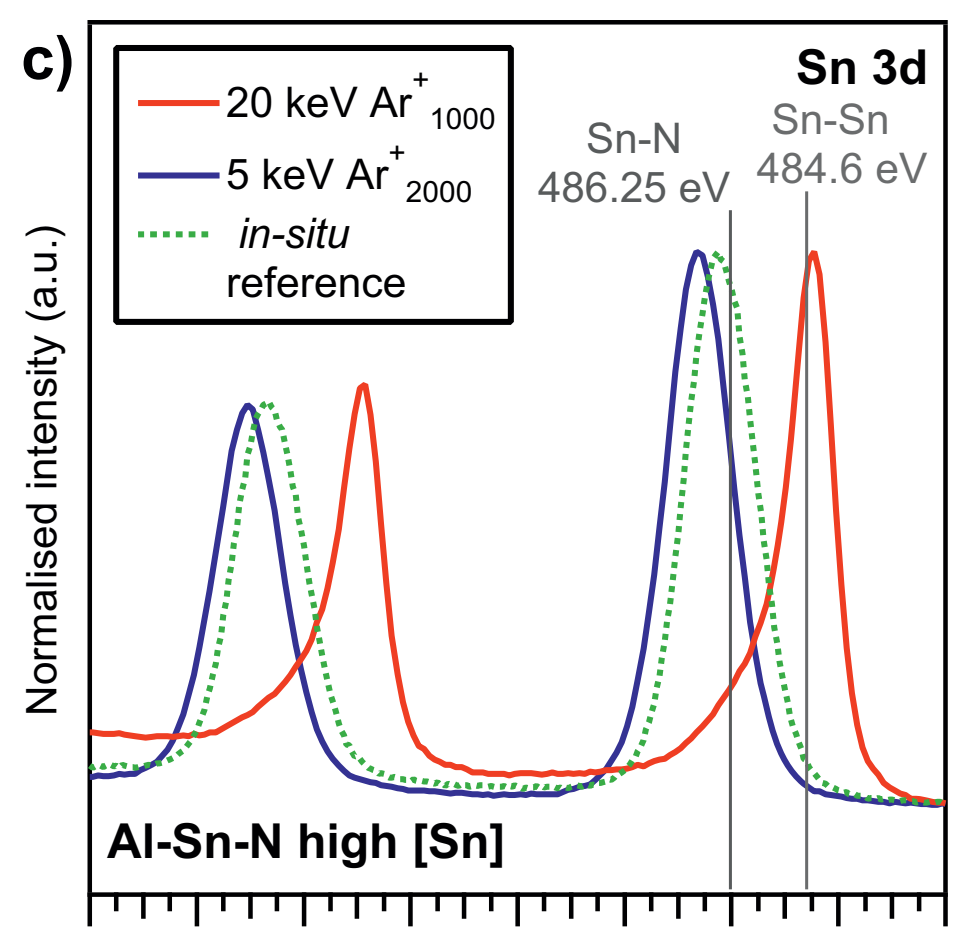

$\begin{array}{lllllllll}498 & 496 & 494 & 492 & 490 & 488 & 486 & 484 & 482\end{array}$ $\mathrm{E}_{\mathrm{B}}(\mathrm{eV})$ [referenced to Al 2p @ $73.6 \mathrm{eV}$ ]
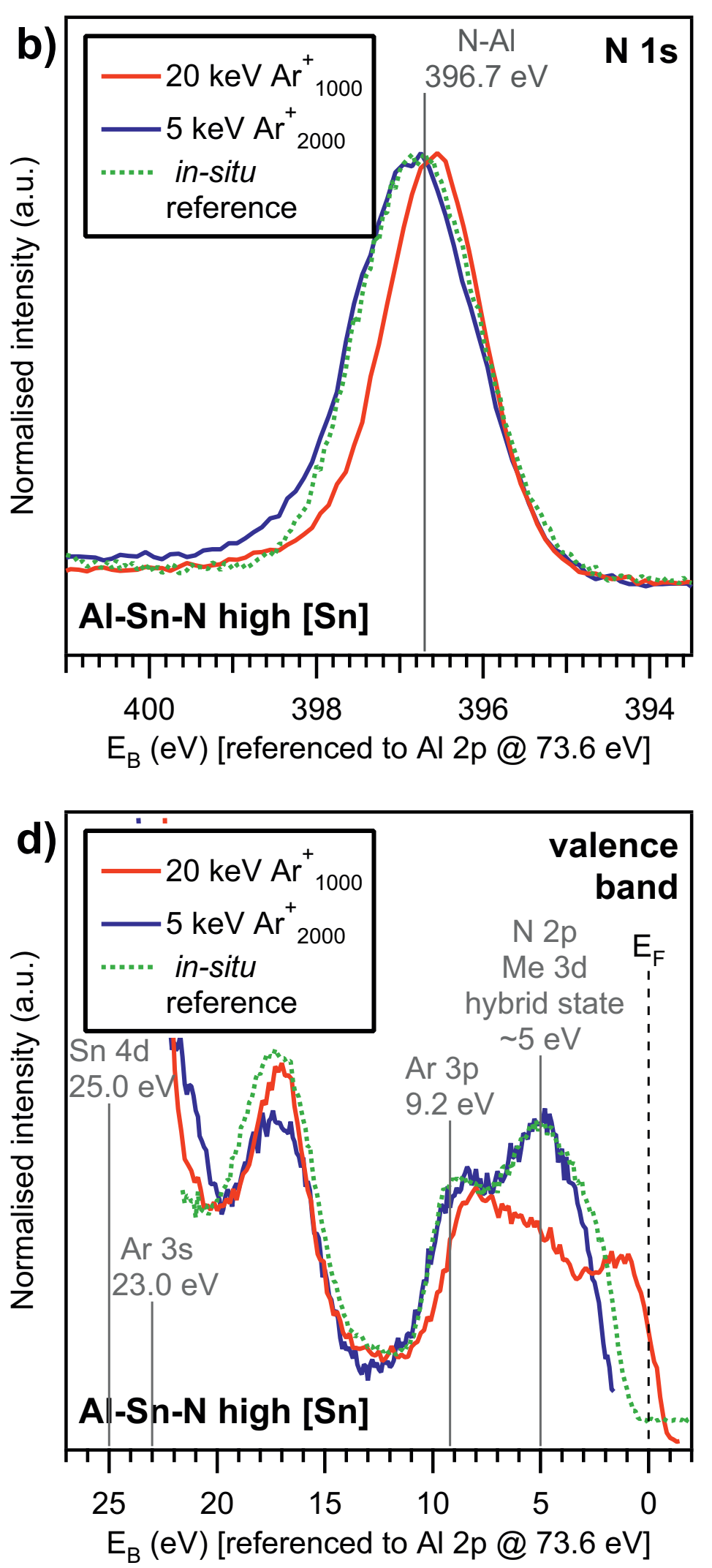


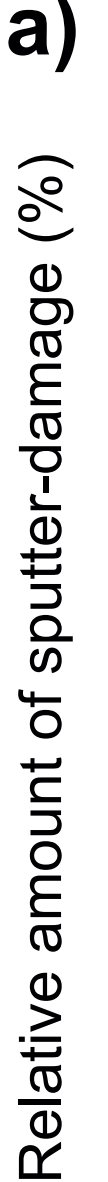

100

80
60
40
20
0

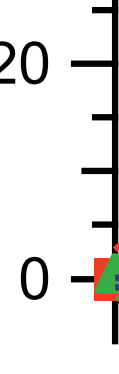

0

200

400

600

Al-Sn-N high [Sn]

Al-Sn-N low [Sn]

Al-Ge-N high [Ge]

$\triangle \mathrm{Al}-\mathrm{Ge}-\mathrm{N}$ low [Ge]

- Al-Si-N high [Si]

- Al-Si-N- low [Si]

$\mathrm{Ar}^{+}$Energy / penetration depth (eV/nm)

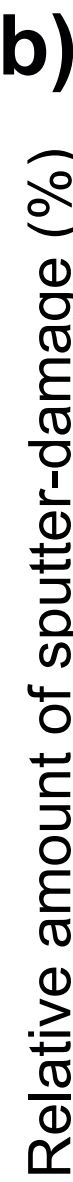

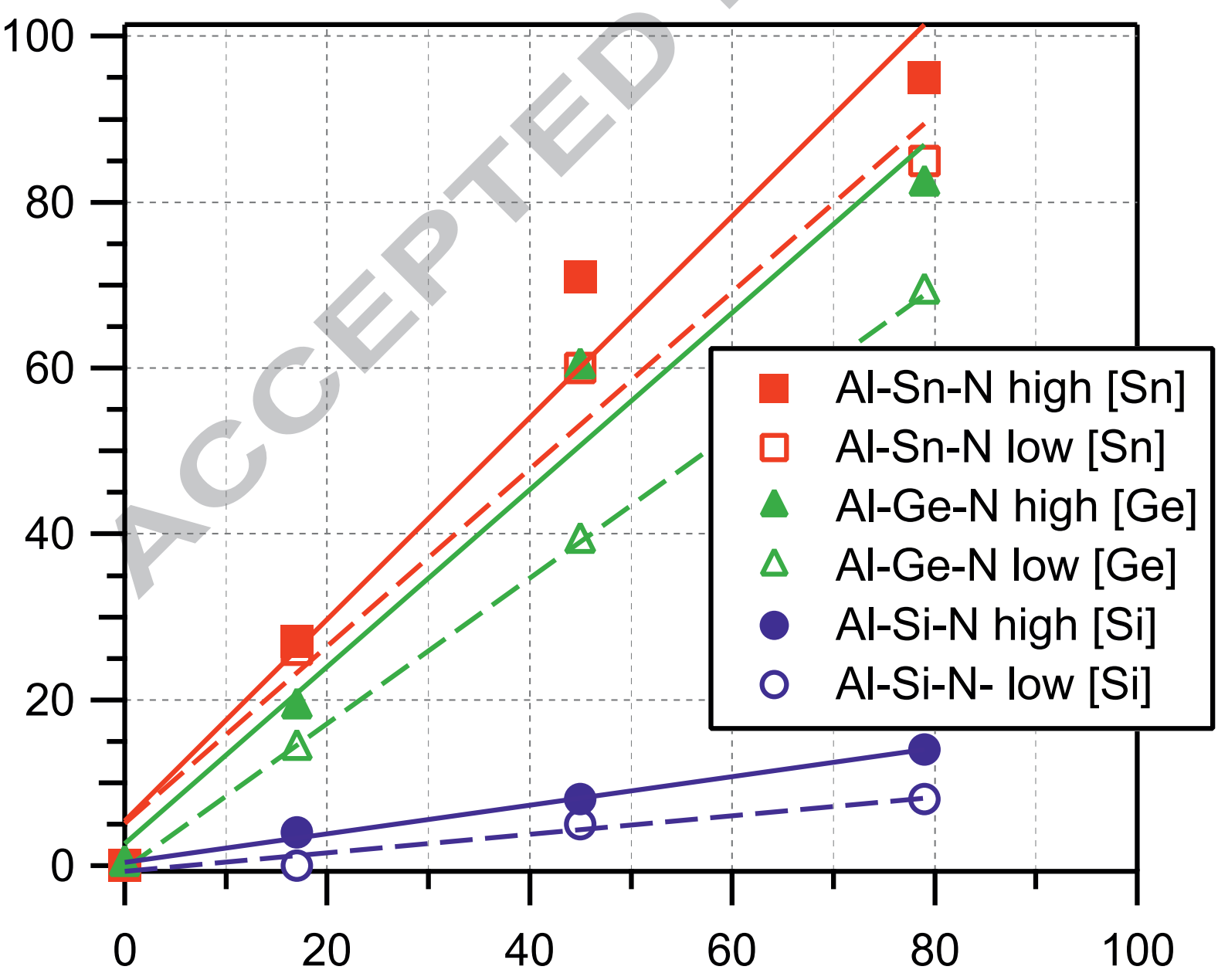

Energy per removed volume $\left(\mathrm{eV} / \AA^{3}\right)$ 
$(\mathrm{kJ} / \mathrm{mol}$ atoms $)$

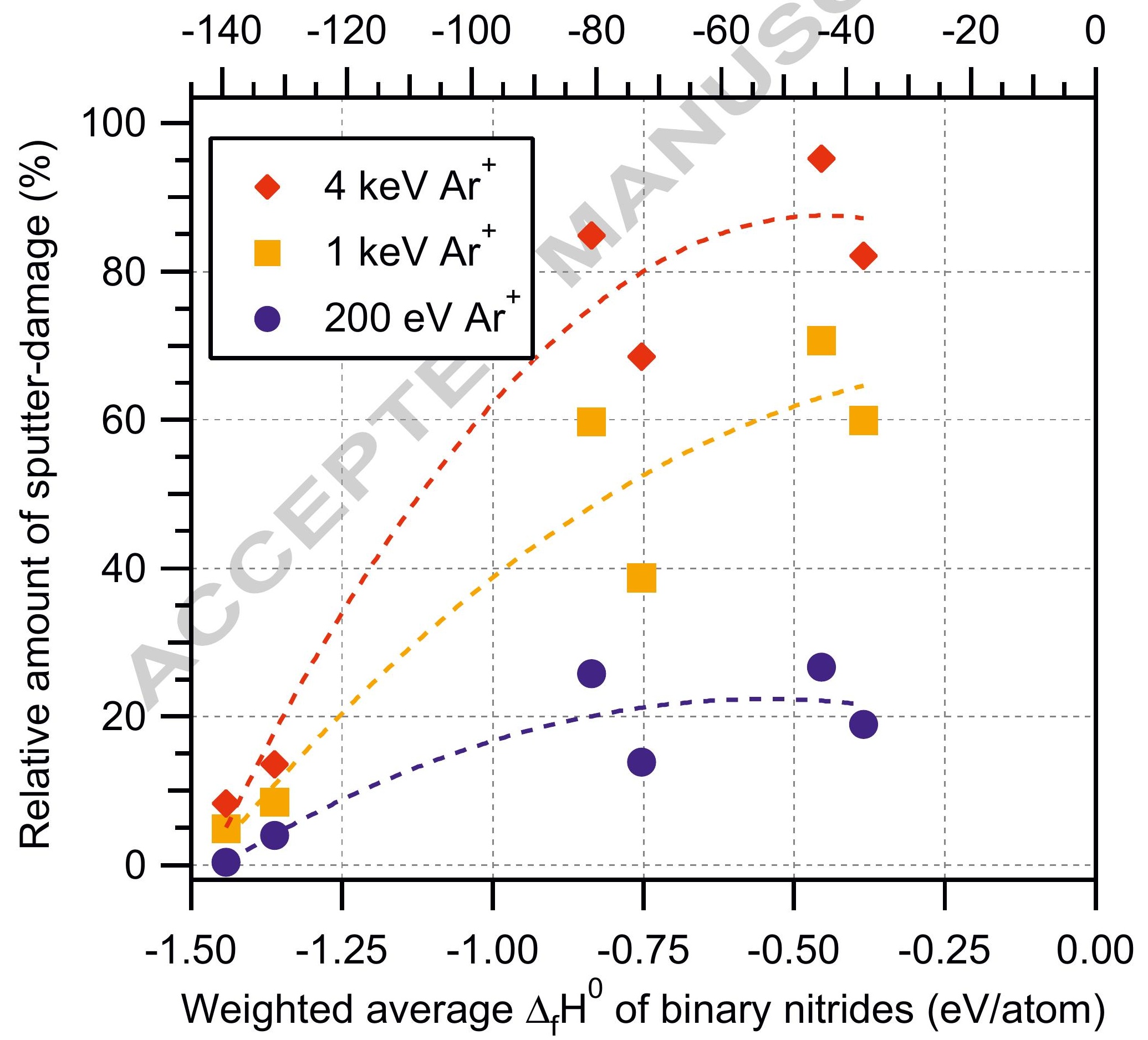



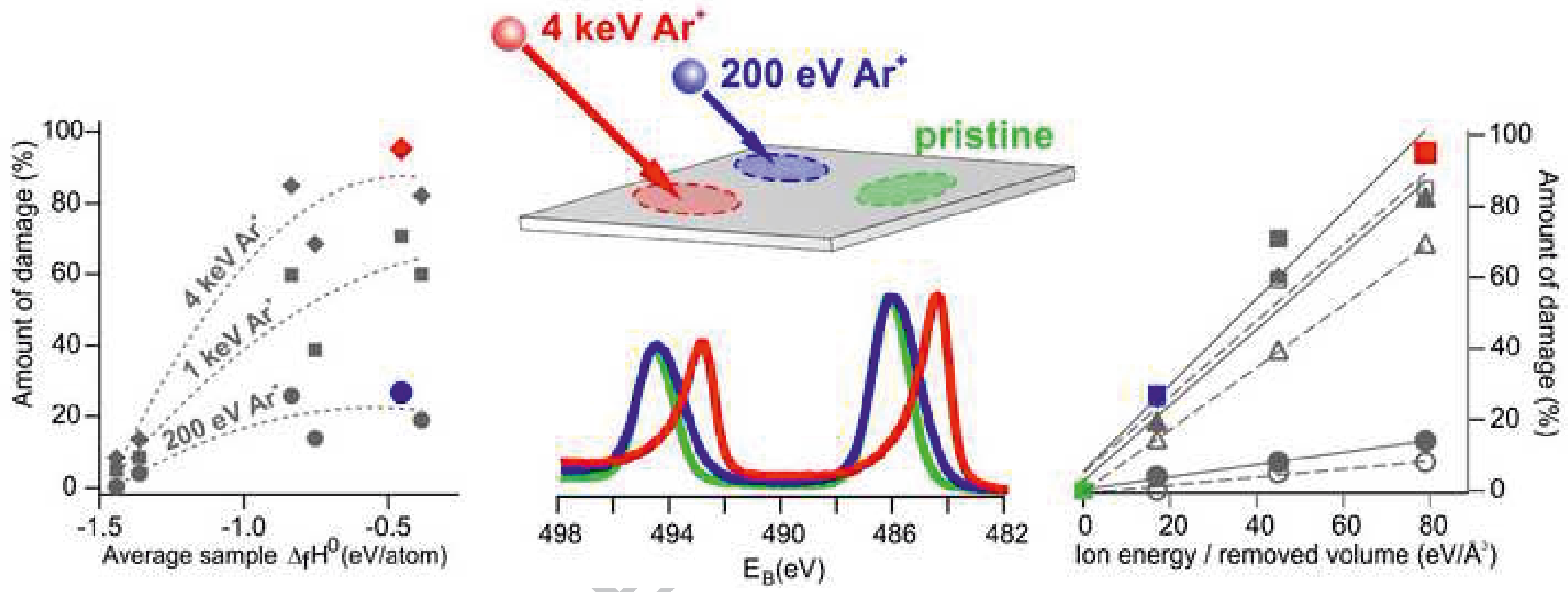


\section{Highlights}

- XPS analysis performed after different ion-etching methods

- Nitride coatings with different (meta)stability investigated

- Sputter-induced artefacts strongly dependent on material (average) formation enthalpy

- Sputter-induced artefacts linearly dependent on energy deposited per removed volume

- Artefact free spectra can be obtained by both monoatomic and polyatomic ion beams 